\title{
Making the Case for a Model Mental Health Advance Directive Statute
}

\author{
Judy A. Clausen ${ }^{*}$
}

\begin{abstract}
:
Acute episodes of mental illness temporarily destroy the capacity required to give informed consent and often prevent people from realizing they are sick, causing them to refuse intervention. Once a person refuses treatment, the only way to obtain care is as an involuntary patient. Even in the midst of acute episodes, many people do not meet commitment criteria because they are not likely to injure themselves or others and are still able to care for their basic needs. Left untreated, the episode will likely spiral out of control. By the time the person finally meets strict commitment criteria, devastation has already occurred. This Article argues that an individual should have the right to enter a Ulysses arrangement, a special type of mental health advance directive that authorizes a doctor to administer treatment during a future episode even if the episode causes the individual to refuse care. The Uniform Law Commissioners enacted the Uniform Health-Care Decisions Act as a model statute to address all types of advance health care planning, including planning for mental illness. However, the Act focuses on end-of-life care and fails to address many issues faced by people with mental illness. For example, the Act does not empower people to enter Ulysses arrangements and eliminates writing and witnessing requirements that protect against fraud and coercion. This Article recommends that the Uniform Law Commissioners adopt a model mental health advance directive statute that empowers people to enter Ulysses arrangements and provides safeguards against abuse. Appendix A sets forth model provisions.
\end{abstract}

* Assistant Professor, Florida Coastal School of Law. B.A., Georgetown University, 1992; J.D., University of Florida, 1995. The author would like to thank her mother, a psychiatric nurse, Judy Lacy, her brother, a psychiatrist, Dr. Benjamin Lacy, professors Heidi Anderson and Joanmarie Davoli, research assistants Dennis Uhlmann, Ashlea Edwards, Nadia Hoosien, and Timothy Wombles, and the participants of the Sixth Annual Florida Legal Scholarship Forum at Stetson University College of Law. 


\section{TABLE OF CONTENTS}

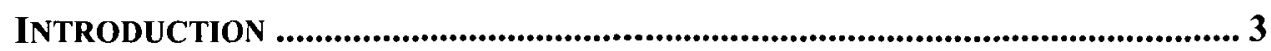

I. Mental Health DiRectives in CONTEXT................................................... 6

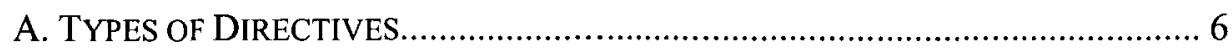

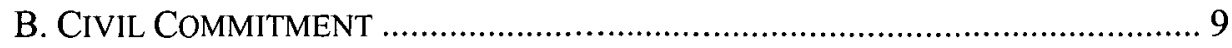

C. BenEFITS of Mental Health DiRectives ............................................. 13

D. ADDRESSING CONCERNS ABOUT ULYSSES ARRANGEMENTS .................... 21

II. ANALYSIS OF THE UNIFORM ACT AND STATE STATUTES ............................. 23

A. SPECIALIZEd StATUTE OR ONE SIZE FITS ALl APPROACH? ....................... 24

B. REVOCATION AND ULYSSES ARRANGEMENTS ……………........................ 27

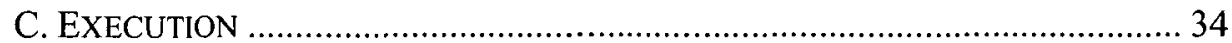

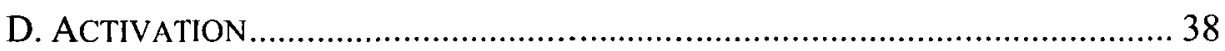

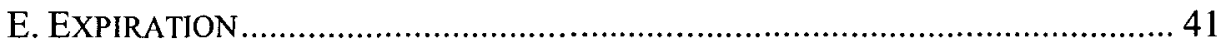

F. Advance Consent to Intrusive Treatments, the Role of Proxies, AND PATIENTS Who FAIL TO PLAN.............................................................. 43

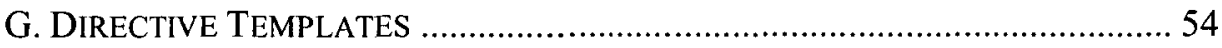

III. SOLUTION: ISSUE A MODEL STATUTE ......................................................... 55

A. PRovisions MAKING DiReCtives EFFeCtive InTERVENTION TOOLS ....... 55

B. Provisions ENSURING Directives are Created Free from Undue

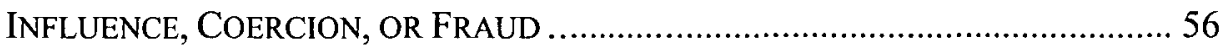

C. SAFEguards ENSURING Directives are Properly IMPLEMENTED AND

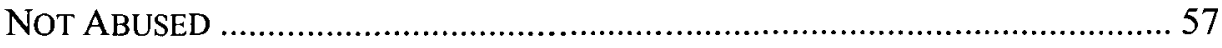

D. Provisions Removing ObSTACles to AdVANCE PlanNING ……..........58

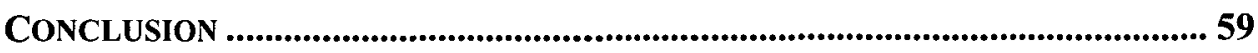

Appendix A: Model Statutory Provisions governing Mental

HEALTH DIRECTIVES................................................................................... 61 
It must be remembered that for the person with severe mental illness who has no treatment the most dreaded of confinements can be the imprisonment inflicted by his own mind, which shuts reality out and subjects him to the torment of voices and images beyond our own powers to describe.

\section{INTRODUCTION}

The Uniform Law Commissioners ("the Commissioners") created the Uniform Health-Care Decisions Act ("the Uniform Act") as a comprehensive model advance directive statute for states to adopt. ${ }^{2}$ The Uniform Act purports to address all types of advance health care planning, including planning for mental illness. ${ }^{3}$ However, the Commissioners focused on end-of-life decision-making, not mental illness. Therefore, the Uniform Act fails people with mental illness in several ways. Half of the states, recognizing that planning for end-of-life care implicates different issucs than planning for mental health treatment, enacted separate mental health directive statutes. However, these statutes also fail to empower patients.

A key failure of the Uniform Act, which will be further discussed in Part II, is that it does not empower patients to form self-binding arrangements for care. ${ }^{4}$ Instead, the Uniform Act states that an individual may revoke her directive at any time. ${ }^{5}$ It does not expressly require capacity for revocation or allow patients to designate whether they may revoke their directives when they lack capacity. Arguably, it prevents patients from forming irrevocable directives and therefore provides no guidance on administering treatment pursuant to an irrevocable directive. For these reasons, the Uniform Act deprives patients of a valuable tool, the Ulysses arrangement.

A Ulysses arrangement is a type of mental health advance directive (mental health directive) that serves as a preventative measure for a patient to obtain treatment during an episode because the patient has learned that episodes cause

1 Olmsted v. Zimring, 527 U.S. 581, 609-10 (1999) (Kennedy, J., concurring in judgment).

2 Nat'l Conference of Comm'rs on Unif. State Laws, Uniform Health-Care Decisions Act, UNIFORM L. COMMISSION (Jan. 12, 1994), http://www.uniformlaws.org/shared/docs/ health\%20care\%20decisions/uhcda_final_93.pdf [hereinafter UHCDA] (The Act superseded the Commissioners' Model Health-Care Consent Act (1982), the Uniform Rights of the Terminally Ill Act (1985), and the Uniform Rights of the Terminally Ill Act (1989).). See generally Charles P. Sabatino, The New Uniform Health Care Decisions Act: Paving a Health Care Decisions Superhighway?, 53 MD. L. Rev. 1238 (1994); Marah Stith, The Semblance of Autonomy: Treatment of Persons with Disabilities Under the Uniform Health-Care Decisions Act, 22 Issues L. \& MED. 39 (2006).

3 UHCDA $\S 1 \mathrm{cmt}$. (stating the health care definition is to be given the broadest construction); see also Maurice S. Fisher, Psychiatric Advance Directives and the Right to Be Presumed Competent, 25 J. ConTEMP. HealTh L. \& POL'Y 386, 397 (2009) (asserting that UHCDA affords patients the ability to make decisions concerning future mental health issues); Sabatino, supra note 2 , at 1240 .

4 UHCDA $\S 3$.

5 UHCDA § 3(a)-(b). 
her to refuse needed intervention. ${ }^{6}$ The patient enters the arrangement when she has capacity. ${ }^{7}$ A Ulysses arrangement authorizes doctors to treat the patient during a future episode when the patient lacks capacity even if the episode causes the patient to refuse treatment at that time. ${ }^{8}$ A patient who enters a Ulysses arrangement essentially requests doctors to ignore the patient's illness-induced refusals. $^{9}$

The following story illustrates why Ulysses arrangements are needed to facilitate intervention. Mr. Smith's daughter begged police to drive to her father's house and transport him to the hospital. Diagnosed with bipolar disorder, he was in the midst of an acute manic episode. His daughter had received letters from him bragging about his upcoming role in a blockbuster film. When Mr. Smith became manic, psychosis led him to a fantasy world in which he starred in a movie filmed by hidden cameras. Police agreed to check on him to determine whether he met the criteria for involuntary emergency detention and hospital admission. Hours later, police informed her that although $\mathrm{Mr}$. Smith acted bizarrely, they could not transport him to the hospital against his will because his behavior did not indicate that he was a danger to himself or others.

A week later, police found Mr. Smith in front of his apartment wearing only underwear and darting into the street. Concerned that a car might hit him, the police decided that he met the criteria and transported him to the hospital against his will. Two weeks of inpatient treatment would bring Mr. Smith back to his gentle self. But 72 hours later, as required by law, doctors discharged Mr. Smith against medical advice even though he was still manic. They explained that he demanded discharge and did not meet involuntary placement criteria. Days later, police arrested Mr. Smith who was driving one hundred and twenty miles an hour on a freeway. Psychosis made him believe that he was in a televised drag race. The jail health clinic gave him lithium but failed to monitor his fluid intake. As a

6 See Elizabeth M. Gallagher, Advance Directives for Psychiatric Care: A Theoretical and Practical Overview for Legal Professionals, 4 PsYCHOL. PUB. POL'Y, \& L. 746, 780 (1998) (providing a sample Ulysses arrangement); I. Gremmen et al., Ulysses Arrangements in Psychiatry: A Matter of Good Care?, 34 J. MED. ETHICs 77, 80 (2008) (preferring the term Ulysses "arrangement" over Ulysses "contract" or "statement" because "contract" overemphasizes the judicial aspects and "statement" has the connotation of a one-sided declaration); Chrisoula Andreou, Making a Clean Break: Addiction and Ulysses Contracts, 22 BIOETHICS 1 (2008) (arguing that there is a place for Ulysses contracts in managing addictive behavior).

7 Gremmen, supra note 6, at 77.

8 See Andreou, supra note 6 , at 1 . The arrangement derives its name from the main character in Homer's epic poem Odyssey. Ulysses was afraid the Sirens' song would lead him into danger. He directed his shipmates to tie him to the mast of his ship and not to release him, even if the Sirens' song manipulated him to demand to be set free. In the mental health context, Ulysses contracts "uphold the guidance provided by one's deepest identity conferring concerns" and potentially prevent episodes from threatening the "self". Theo Van Willigenburg \& Patrick J.J. Belaere, Protecting Autonomy as Authenticity Using Ulysses Contracts, J. MED. \& PHIL. 395, 397 (2005).

9 See Breanna M. Sheetz, Comment, The Choice to Limit Choice: Using Psychiatric Advance Directives to Manage the Effects of Mental Illness and Support Responsibility, 40 U. MICH. J.L. REFORM 401, 403 (2007). 
result he suffered lithium toxicity, making it medically unsafe for him to take lithium. He must now rely on other treatments.

Before the onset of his illness, Mr. Smith was a mild-mannered accountant. When he takes his medication, he is still that person. Manic episodes have given him a criminal record and cost him his marriage, his career, two years of commitment in a state psychiatric hospital, and his savings. Mr. Smith wants to prevent further damage to his life by forming a Ulysses arrangement.

Acute episodes of mental illness often prevent people like Mr. Smith from realizing they are sick and cause them to refuse treatment. ${ }^{10}$ Once an episode causes a person to refuse care, the primary means of obtaining treatment is through involuntary commitment. ${ }^{11}$ Even in the midst of acute episodes that have temporarily destroyed capacity, many people do not meet commitment criteria because they are not likely to injure themselves or others and are still able to care for their basic needs. ${ }^{12}$ Requiring a person to reach a state that meets involuntary commitment criteria can postpone intervention until it is too late. ${ }^{13}$

This Article proposes a solution that empowers people to control their mental illnesses. Part I places mental health directives in context and begins with a description of the types of advance directives. Section I.B explains civil commitment law because a basic understanding of commitment law is necessary to appreciate the need for Ulysses arrangements. Section I.C explores the key benefit of Ulysses arrangements: to intervene early and avoid involuntary commitment. Then, it explores the benefits of mental health directives generally. Section I.D identifies and addresses concerns that Ulysses arrangements are paternalistic, create opportunities for abuse, violate due process, fail to provide contemporaneous informed consent, and destroy privacy.

Part II explores key provisions of the Uniform Act and state statutes. Section II.B compares the Uniform Act and state mental health directive statutes,

10 See Kay Redfield Jamison, An Unquiet Mind: A Memoir of Moods and Madness 36 (1995); Joanmarie I. Davoli, Still Stuck in the Cuckoo's Nest: Why Do Courts Continue to Rely on Antiquated Mental Illness Research?, 69 TENN. L. REv. 987, 1009 (2002) (asserting that inability to accept that one is mentally ill is a symptom of the disease); NAT'L ETHICS COMM.,VETERANS Health Admin., AdVANCE DiRECTIVES FOR MENTAL HEALTH: AN ETHICAL ANAL YSIS OF STATE LAWS \& implications for VHa Policy, Nat'L Center for Ethics in Health Care, U.S. Dep't Veterans AfF. 8 (Feb. 2008), http://www.ethics.va.gov/docs/necrpts/NEC_Report_20080220_Adv_ Directives_MH-Analysis_of_State_Laws-Implications_for_VHA_Policy.p̄pdf [hereinafter -VHĀ Report] (asserting that patients entering a mania may not recognize they are sick and may refuse treatment).

11 See Sheetz, supra note 9, at 415.

12 See infra Section I.C.

13 Nick Anderson, Dr. Jekyll's Waiver of Mr. Hyde's Right to Refuse Medical Treatment: Washington's New Law Authorizing Mental Health Care Advance Directives Needs Additional Protections, 78 WASH. L. REv. 795, 801 (2003) (relaying testimony summarized by a legislative assistant); Davoli, supra note 10, at 1045 (citing Ashok K. Malla et al., Improving Outcomes in Schizophrenia: The Case for Early Intervention, 160 CAN. MED. Ass'N J. 843, 844 (1999) for the proposition that early intervention at the onset of psychosis improves the odds of long-term recovery). 
concluding that neither adequately empowers patients to form Ulysses arrangements. Section II.C illustrates why the Uniform Act's minimal execution requirements expose patients to risks of coercion, fraud, and undue influence. Section II.D commends the Uniform Act's patient designated activation because it facilitates early intervention. Section II.E discusses when automatic expiration of mental health directives may be appropriate. Section II.F illustrates that the Uniform Act's lack of guidance on mental health treatments combined with unchecked authority to automatically selected surrogates undermines patient autonomy and potentiates abuse.

Part III explains key provisions of a model mental health directive statute set forth in Appendix A that empower patients to enter Ulysses arrangements and safeguard against abuse.

\section{Mental Health DiRectives in Context}

This Part describes the status quo, which must be understood to better appreciate the need for a model statute that empowers patients to form Ulysses arrangements. Section I.A explores types of directives and explains the context in which mental health directives are implemented. Section I.B gives an overview of civil commitment law which is often the only intervention available for patients unable to form Ulysses arrangements. Section I.C explains the key benefit of a Ulysses arrangement: to intervene early and avoid commitment. Then it explains the benefits of mental health directives generally. Section I.D identifies and addresses concerns about Ulysses arrangements.

\section{A. Types of Directives}

Advance directives come in various forms.$^{14}$ Instructional directives enable a patient (also known as the principal) to instruct doctors to administer care when the patient lacks capacity to provide informed consent. ${ }^{15}$ Capacity, a key concept in this Article, refers to the capacity to make and communicate health care decisions and to "understand the significant benefits, risks, and alternatives" to proposed treatment. ${ }^{16}$ Proxy directives allow a patient to appoint an agent to make health care decisions for the patient when the patient is incapacitated. ${ }^{17}$ Hybrid directives contain instructions and designate agents. ${ }^{18}$ Patients use these forms of directives for physical as well as mental illness. ${ }^{19}$ Directives intended to

14 Justine A. Dunlap, Mental Health Advance Directives: Having One's Say, 89 KY. L.J. 328, 347-54 (2001).

15 See John Q. La Fond \& Deborah Srebnik, The Impact of Mental Health Advance Directives on Patient Perceptions of Coercion in Civil Commitment and Treatment Decisions, 25 INT'L J.L. \& PSYCHIATRY 537-40 (2002).

16 UHCDA $\S 1(3)$.

17102 AM. JUR. 3D Proof of Facts § 25 (last updated Sept. 2013).

18 La Fond \& Srebnik, supra note 15, at 541.

19 Proof of Facts, supra note 17, at $\S \S 7,25$. 
plan for episodes of mental illness are called mental health directives. ${ }^{20}$ The Ulysses arrangement is a special type of mental health directive that is irrevocable during periods of incapacity and enables the patient to consent in advance to treatment despite illness-induced refusals. ${ }^{21}$ Acute episodes of mental illness often act directly to deprive patients of capacity and can distort judgment more than physical illnesses of similar severity. ${ }^{22}$ Such episodes often cause patients to refuse treatment to which they would consent if they were not influenced by the episode. ${ }^{23}$ For this reason, clinicians implement mental health directives, including Ulysses arrangements, in a different context than they implement general advance directives (generic directives). ${ }^{24}$ Professor Patricia Backlar stated that a generic directive attempts to guarantee a "good death" while a mental health directive endeavors to secure a "good life."25 Generally, doctors implement instructions regarding end-of-life treatment contained in a generic directive when the patient is in a coma ${ }^{26}$ Unlike comatose patients, a patient in the midst of an acute mental illness episode is capable of taking affirmative actions, which suggests the need for a different precautionary scenario. Doctors often must implement mental health directives during episodes in which the patient is not only conscious but unruly. ${ }^{27}$ In the midst of such episodes, patients may adamantly refuse treatment requested in their directives. ${ }^{28}$ Moreover, people with chronic terminal illness are more likely to receive treatment from doctors with whom they have established relationships than are people with episodic mental illness. Acute episodes of mental illness can induce people to travel, and they often receive treatment for acute episodes of mental illness in emergency rooms or, after arrest, in jails. ${ }^{29}$ It is essential that mental health directives are

20 See Richard A. Van Dorn et al, Reducing Barriers to Completing Psychiatric Advance Directives, 35 Admin. \& POL'Y Mental Health 440, 448 (2008).

21 See Dunlap, supra note 14, at 352-55.

$22 \mathrm{Id}$.

23 See supra note 10 and accompanying text.

24 Patricia Backlar, Anticipatory Planning for Psychiatric Treatment Is Not Quite the Same as Planning for End-of-life Care, 33 Community Mental Health J. 262 (1997).

25 Id. at 261-62.

26 See David Y. Nakashima, Comment, Your Body, Your Choice: How Mandatory Advance Health-Care Directives Are Necessary to Protect Your Fundamental Right to Accept or Refuse Medical Treatment, 27 U. HAw. L. REv. 201, 202-03 (2004) (discussing In re Guardianship of Schaivo, 780 So. 2d 176, 177 (Fla. Dist. Ct. App. 2001), in which the family of a woman in a persistent vegetative state battled over whether she should be kept alive through artificial means and stating that generic directives address situations like persistent vegetative states); Dunlap, supra note 14 , at $356-58$.

27 Robert D. Miller, Advance Directives for Psychiatric Treatment: A View from the Trenches, 4 PSYCHOL. PUB. POL'Y \& L. 728, 734 (1998).

28 See supra note 10 and accompanying text.

29 See Pete Earley, Crazy: A Father's Search Through america's Mental Health MADNESS 2-3 (2006) (The largest public mental health facility in America is the Los Angeles County jail, which on any given day houses 3000 mentally disturbed inmates); Bureau of Justice Statistics, Special Report: Mental Health Problems of Prison and Jail Inmates, OFF. JusT. 
enforceable wherever patients receive care.

The Uniform Act focuses on the typical end-of-life situation. ${ }^{30}$ The Commissioners approved the Uniform Act because state laws for advance directives were incomplete, inconsistent, and confusing. ${ }^{31}$ The Commissioners are all practicing attorneys, judges, legislators, legislative staff, or law professors appointed by state governments to research, craft, and promote uniform state laws in areas where uniformity is desirable and practical. ${ }^{32}$ At the time the Uniform Act was issued, every state had one or more statutes regarding health care powers of attorney, living wills, or other forms of proxy decision-making. ${ }^{33}$ Often, these statutes were incomplete because they only addressed a narrow set of issues or were overly formalistic and difficult for patients to follow. ${ }^{34}$ The primary goals of the Uniform Act were to support patient autonomy by creating a simplified uniform process to facilitate use of advance directives and provide a method for making health care decisions when patients fail to plan. ${ }^{35}$ The Commissioners simplified the formation process by dispensing with obstacles to directive formation such as requirements for a signed, witnessed, notarized writing. ${ }^{36}$ The Uniform Act purported to be a comprehensive statutory scheme addressing all health care planning. ${ }^{37}$ With its focus on end-of-life, the Uniform Act is not suited to the mental health context for a host of reasons explored in Part II of this paper. Most importantly, the Uniform Act does not expressly authorize patients to specify whether they may revoke their directives when they lack capacity. ${ }^{38}$ It also does not expressly require capacity for revocation. ${ }^{39}$ This is probably why the Uniform Act provides no guidance for administration of treatment pursuant to an irrevocable directive in the face of illness-induced refusals. For these reasons, the Uniform Act does not empower patients to form Ulysses arrangements. Without a Ulysses arrangement, a patient whose illness causes him to revoke his directive and refuse treatment has no mechanism to secure intervention unless he meets involuntary commitment criteria.

Even though state mental health directive statutes typically prohibit

Programs, U.S. DeP'T JuSTICE, http://www.bjs.gov/content/pub/pdf/mhppji.pdf (last updated Dec. 14,2006 ) (In 2005, more than half of all inmates had a mental health problem.).

30 See infra Part II.

31 David M. English, The Uniform Health-Care Decisions Act and its Progress in the States, 15 Prob. \& Prop. 19 (2001).

32 See An Introduction to the Uniform Law Commission, Uniform Law Comm'N (July 2, 2012),

http://www.uniformlaws.org/Video.aspx?title=An\%20Introduction\%20to\%20the\%20Uniform\%20 Law\%20Commission.

33 Sabatino, supra note 2, at 1238.

34 Id.

35 English, supra note 31 , at 20.

36 UHCDA § 2(a) (specifying that individual instructions "may be oral or written").

37 English, supra note 31 , at 20.

38 See UHCDA $\S 3$ (describing revocation procedures, none of which allow principals to designate whether directives are revocable when the principal lacks capacity).

$39 \mathrm{Id}$. 
incapacitated patients from revoking their directives, they do not empower patients to form Ulysses arrangements. These statutes do not set forth procedures for treating patients pursuant to Ulysses arrangements. The insufficient protection that mentally ill patients receive from these statutes will be discussed at greater length in Section II.B. Without a process for administering treatment pursuant to a Ulysses arrangement, providers will discharge patients who demand discharge even if their irrevocable directives consent to treatment. This is because without a statute authorizing clinicians to administer treatment pursuant to a Ulysses arrangement, clinicians will refuse to admit and treat in the face of the patient's refusals. Doing so could expose the clinician or hospital to liability for various torts, including violating informed consent, assault, battery, false imprisonment, statutory violations, and federal civil rights violations explored in Section I.C.

\section{B. Civil Commitment}

If a patient is unable to form a Ulysses arrangement, the primary means of obtaining intervention during an episode that causes him to refuse treatment is through involuntary civil commitment. ${ }^{40}$ The state's authority to commit people with mental illness derives from two components of sovereignty. ${ }^{41}$ The first is the police power, which is the authority to maintain peace and order. ${ }^{42}$ The state can confine a person who is likely to be dangerous to others. ${ }^{43}$ The second is the parens patriae power, which enables the state to protect a person whose mental illness makes her likely to harm herself or prevents her from being able to care for her basic needs. ${ }^{44}$

\section{Criteria}

According to the U.S. Supreme Court, civil commitment imposes a "massive curtailment of liberty, ${ }^{, 45}$ that warrants strict commitment criteria. The Supreme Court decided that the clear and convincing evidence standard meets due process guarantees for civil commitment proceedings, but the preponderance of the evidence standard is inadequate. ${ }^{46}$

For police power commitment, states typically require the government to show that because of mental illness, the person is a danger to others. ${ }^{47}$ First, the

40 Sheetz, supra note 9 , at 415 .

41 Addington v. Texas, 441 U.S. 418, 426 (1979).

$42 \mathrm{Id}$.

$43 \mathrm{Id}$.

44 Id.

45 Zinermon v. Burch, 494 U.S. 113, 131 (1990); Vitek v. Jones, 445 U.S. 480, 491-92 (1980); Humphrey v. Cady, 405 U.S. 504, 509 (1972).

46 Addington, 441 U.S. at $432-33$.

47 Christopher Slobogin et al., Law and the Mental Health System: Civil and Criminal Aspects 23, 705 (5th ed. 2008). 
state must prove the person suffers from a mental illness or disorder, ${ }^{48}$ often defined as a substantial disorder of the emotional processes, thought or cognition that grossly impairs judgment, behavior or capacity to recognize reality. ${ }^{49}$ Second, most states require proof that mental illness caused the dangerousness. ${ }^{50}$ Third, the government must prove the dangerousness itself. ${ }^{51}$ The standards for dangerousness vary by jurisdiction. For instance, in Florida the government must show a substantial likelihood that in the near future the person will inflict serious bodily harm on another person, as evidenced by recent behavior causing, attempting, or threatening such harm. ${ }^{52}$ Florida is one of several states that demand a finding of an overt act as a prerequisite to involuntary civil commitment. ${ }^{53}$ Not all jurisdictions have an overt act requirement. ${ }^{54}$

For parens patriae commitment, states generally require the government to prove that mental illness caused the person to be a danger to herself or rendered her unable to provide for her basic needs. ${ }^{55}$ Generally, states use the same definition of mental illness or disorder as used for police power commitment. ${ }^{56}$ Two categories of people are potentially subject to parens patriae commitment. The first is people at risk of suicide or self-harm caused by provocation of others. ${ }^{57}$ The second is people whose illnesses render them unable to provide for their basic needs for food, clothing, and shelter. ${ }^{58}$ Typically, states that have an overt act requirement for police power commitment have the requirement for parens patriae commitment. ${ }^{59}$

For both types of involuntary commitment, almost all states require consideration of less restrictive alternatives to involuntary hospitalization ${ }^{60}$ that

48 Foucha v. Louisiana, 504 U.S. 71, 112 (1992); SLOBOGIN ET AL., supra note 47, at 723; William P. Coyle, Cause of Action Against Psychiatrist in State-Operated Psychiatric Facility for Improper Civil Commitment, in 10 CAUSES ACTION 2D 1, \$4 (last updated Oct. 2013).

49 Slobogin ET AL., supra note 47, at 723; see, e.g., N.M. STAT. ANN. § 43-1-3(O) (2013).

50 SLOBOGIN ET AL., supra note 47 , at 726.

51 Id. at 726-42 (generally addressing dangerousness); Coyle, supra note 48, at $\S 4$; see, e.g., In re B.T., 891 A.2d 1193 (N.H. 2006) (requiring evidence of dangerous conduct and stating the psychiatrist's finding of a dangerous mental condition is insufficient for involuntary commitment).

52 FLA. STAT. $\$ 394.467(1)$ (b) (2013).

53 See, e.g., Kan. STAT. ANN. \$59-2946(f) (2013); Lessard v. Schmidt, 349 F. Supp. 1078 (E.D. Wis. 1972), vacated, 414 U.S. 473 (1974).

54 Matthew v. Nelson, 461 F. Supp. 707 (N.D. Ill. 1978); MiChaEl L. Perlin, Mental DisabILITY LAW 119 (2d ed. 2005).

55 Slobogin ET AL., supra note 47 , at 705.

56 See supra notes $48-49$ and accompanying text.

57 Donald H.J. Hermann, Mental Health and Disability Law in a Nutshell 159 (1997).

58 PERLIN, supra note 54, at 125 (This form of parens patriae commitment is often called "gravely disabled."); Doe v. Gallinot, 486 F. Supp. 983 (C.D. Cal. 1979), affd, 657 F.2d 1017 (9th Cir. 1981) (stating that the gravely disabled standard meets constitutional standards but cautioning against overbroad construction).

59 HERMANN, supra note 57, at 161.

60 SLOBOGIN ET AL., supra note 47 , at 782; see, e.g., FlA. STAT. $\S 394.467(1)$ (b) (2013) (prohibiting involuntary commitment without a finding that all available less restrictive treatment alternatives were adjudged inappropriate); HAw. REV. STAT. $\S 334-60.2$ (2013). 
allow for care and prevent danger, such as outpatient treatment, day or night treatment in a hospital, placement in the custody of a loved one, or home health services. ${ }^{61}$

\section{Procedures}

\section{Emergency Detention and Screening}

All states authorize involuntary emergency admission and evaluation without a full adjudicatory commitment hearing. ${ }^{62}$ This is the most common way a person enters the civil commitment process. ${ }^{63}$ Usually, either police apprehend and transport the person to a facility or family transports the person. ${ }^{64}$ Typically, statutes authorize police to detain and transport to a hospital a person that the officer concludes meets emergency detention and screening criteria, which are essentially the same criteria for involuntary commitment. ${ }^{65}$ Then, a doctor at the receiving facility examines the person to determine if emergency treatment is necessary to protect the safety of the person or others. ${ }^{66}$ States vary as to who may authorize involuntary emergency admission. ${ }^{67}$ For example, in Virginia, only a magistrate may authorize emergency admission, but in Florida, a doctor can. ${ }^{68}$ States also impose strict time limits under which a person may be subject to involuntary admission and examination. ${ }^{69}$ For example, in Florida, within 72 hours from the time the person arrives at the facility, a mental health professional must examine the person to determine if she meets involuntary placement criteria. ${ }^{70}$ If the person fails to meet the criteria, the facility must release her unless the person provides informed consent to remain as a voluntary patient. ${ }^{71}$

\section{Involuntary Admission}

Every state has formal adjudicatory procedures for involuntary commitment. ${ }^{72}$ Each state requires a formal commitment hearing, ${ }^{73}$ with notice ${ }^{74}$

61 Randolph v. Cervantes, 950 F. Supp. 771, 777 (S.D. Miss. 1996).

62 HERMANN, supra note 57, at 165.

63 Id. at $146-48$.

64 Coyle, supra note 48 , at $\S 2$.

65 See, e.g., FLA. STAT. § 394.463(2) (2013).

66 Id. $\S 394.463$.

67 SLOBOGIN ET AL., supra note 47 , at 807.

68 Fla. STAT. § 394.463 (2013); VA. COde ANN. § 37.2-809 (2013).

69 SLOBOGIN ET AL., supra note 47 , at 811 ; see, e.g., VA. CODE ANN. $\$ 37.2-809$ (stating the duration of temporary detention shall not exceed 48 hours before there is a hearing).

70 FLA. STAT. § 394.463(2) (2013).

$71 \mathrm{Id}$.

72 SLOBOGIN ET AL., supra note 47, at 705.

73 See, e.g., FLA. STAT. § $394.467(6)$ (2013) (hearing to be held within five days).

74 See, e.g., ID. § 394.4599 (2013). 
and counsel, ${ }^{75}$ and mandates periodic reviews of the legal status of committed respondents to evaluate whether they continue to meet commitment criteria. ${ }^{76}$ In most states, a judge makes the decision to commit, but many states enable the respondent to request a jury trial. ${ }^{77}$ Commitment hearings are often dehumanizing. ${ }^{78}$ Many states either provide for private proceedings or allow exclusion of the respondent if being present could be harmful to the respondent. ${ }^{79}$ Generally, states require a review hearing after initial commitment, usually from between three months to a year after admission. ${ }^{80} \mathrm{~A}$ respondent can obtain judicial review through habeas corpus. ${ }^{81}$

\section{Voluntary Admission}

States allow for voluntary admission for inpatient mental health treatment without a hearing. ${ }^{82}$ According to some estimates, over half of psychiatric inpatient admissions are voluntary. ${ }^{83}$ Most clinicians prefer voluntary over involuntary admission because: (1) voluntary patients are more likely to cooperate in treatment; (2) voluntary admission is less stigmatizing; and (3) involuntary commitment proceedings squander medical and judicial resources. ${ }^{84}$ Generally, courts and legislatures also prefer voluntary treatment. ${ }^{85}$ Critics of voluntary admission argue that admission is not truly voluntary because family and doctors frequently coerce patients to admit themselves to avoid involuntary commitment ${ }^{86}$ and patients often lack the capacity necessary to consent to admission. ${ }^{87}$

75 See, e.g., MASS. GEN. LAws ch. 123, § 5 (2013).

76 SLOBOGIN ET AL., supra note 47 , at 705.

$77 \mathrm{Id}$. at 820 . Nebraska is one of a small number of states allowing an administrative board to commit. NeB. Rev. STAT. \$ 71-915 (2013).

78 Karna Halverson, Voluntary Admission and Treatment of Incompetent Persons with a Mental Illness, 32 WM. MiTCHELL L. Rev. 161, 162 (2005).

79 See, e.g., Fla. StAT. $\$ 394.467(6)$ (a) (2013); SLOBOgin ET AL., supra note 47, at 827.

80 Fasulo v. Arafeh, 378 A.2d 553 (1977); SLOBOGIN ET AL., supra note 47, at 852.

81 See, e.g., FLA. STAT. $\$ 394.459$ (2013).

82 See, e.g., id. $\$ 394.4625$ (2013) (providing procedures for voluntary admission and requiring discharge of voluntary patients who request discharge).

83 See Halverson, supra note 78 , at 163 n.4.

$84 \mathrm{ld}$. at 164.

85 Michael L. Perlin, Competency, Deinstitutionalization, and Homelessness: a Story of Marginalization, 28 Hous. L. REv. 63, 116 n.305 (1991).

86 See, e.g., In re Tiffin, 646 N.E.2d 285 (Ill. App. Ct. 1995) (discussing a statute prohibiting statements that the patient may be subject to involuntary commitment if she does not admit herself); see also Halverson, supra note 78, at 166-68 (exploring arguments against voluntary admission including potential for patient coercion and lack of an adversarial process and attorney representation).

87 See, e.g., Zinermon v. Burch, 494 U.S. 113, 113 (1990); Perlin, supra note 85, at 117 (asserting that because most statutes fail to define the competency required for a valid voluntary admission, many patients who consent are incompetent). 


\section{Benefits of Mental Health Directives}

This section first illustrates how Ulysses arrangements empower patients to intervene early and avoid commitment. Next, it enumerates the benefits of mental health directives, which include documenting informed consent (which in turn protects clinicians and facilitates treatment), improving care, safeguarding rights to refuse treatment, and avoiding guardianship.

\section{Intervene Early and Avoid Involuntary Commitment}

Forming a Ulysses arrangement is critical for some patients because it is the only effective intervention mechanism for episodes that compromise their ability to recognize their need for treatment. Involuntary commitment is the most common way patients without directives obtain intervention during an episode. ${ }^{88}$ As explored below, Ulysses arrangements are superior to involuntary commitment because involuntary commitment comes too late and is often traumatic; the proceedings can be dehumanizing; and police apprehension can be dangerous.

The first reason early intervention through a Ulysses arrangement is better than involuntary commitment is that involuntary commitment comes too late. One patient testified, "When someone is allowed to decompose so severely before they can get help under the involuntary treatment act, they never come back quite the same." 89 Pete Earley chronicled his struggles navigating the labyrinth of the mental health system for his son whose illness prevented him from recognizing he needed treatment:

My son was so out of control the nurse called hospital security. I was glad. Maybe now they will medicate him, I thought. But before the security guard arrived, Mike dashed outside, cursing loudly. I went after him. Meanwhile, the doctor told my ex-wife it was not illegal for someone to be mentally ill in Virginia. But it was illegal for him to treat them unless they consented. There was nothing he could do. "Even if he is psychotic?" She asked. "Yes." Mike couldn't forcibly be treated, the doctor elaborated, until he hurt himself or someone else. ${ }^{90}$

The second reason intervention through a Ulysses arrangement is superior to involuntary commitment is that involuntary hospitalization in a state hospital often traumatizes patients..$^{11}$ Patients may suffer symptoms of posttraumatic

88 Sheetz, supra note 9 , at 414 .

89 Anderson, supra note 13 , at 801.

90 EARLEY, supra note 29, at 16.

91 Cf. Letter from Thomas E. Perez, Assistant Att'y Gen., Civil Rights Div., U.S. Dep't of Justice, to the Honorable Sonny Perdue, Ga. Office of the Governor 2 (Dec. 8, 2009), available at $\mathrm{http} / / / \mathrm{www}$.justice.gov/crt/about/spl/documents/Georgia_Psychiatric_Hospitals_findlet_12-08- 
stress disorder after discharge from a state psychiatric hospital. ${ }^{92}$ Loved ones can only visit during limited hours. ${ }^{93}$ There has been evidence of staff members verbally and even physically assaulting patients. ${ }^{94}$ For these reasons, patients may want to consent to admission, at the first signs of an acute episode in a private hospital. Generally, patients prefer treatment from their psychiatrists whom they trust and who know their history. ${ }^{95}$

The third reason to avoid involuntary commitment through a Ulysses arrangement is that involuntary commitment proceedings can be timeconsuming, highly intrusive, and demeaning. ${ }^{96}$ In commitment hearings, patients may witness the testimony of loved ones about the patient's behaviors during acute episodes. Patients may feel like the accused in a criminal trial.

Finally, a Ulysses arrangement potentially enables people suffering from acute episodes to avoid police apprehension, which is the typical way a person enters the commitment process. ${ }^{97}$ For the mentally ill, police encounters can be dangerous. ${ }^{98}$ For example, in Drummond v. City of Anaheim, a police encounter with Drummond, a nonviolent person with bipolar disorder and schizophrenia, resulted in officers brutally knocking Drummond unconscious, ultimately leaving Drummond in a vegetative state. ${ }^{99}$

Document Informed Consent, Protecting Clinicians and Facilitating and Improving Care

Under modern informed consent law, physicians must provide patients relevant information about the risks and benefits of any proposed treatment and obtain the patient's informed consent before administering treatment. ${ }^{100}$ Applying

09.pdf (reporting on an investigation of Georgia's state-nun psychiatric hospitals). The Department found that Georgia's facilities "continue to provide deficient services that subject patients both to actual harm, and to excessive risk of serious harm, including: (1) inadequate protection from harm; (2) inappropriate mental health treatment; (3) inappropriate seclusion and restraints; [and] (4) inadequate medical care."

92 Cf. Civil Commitment of the Mentally Ill, 87 HARv. L. Rev. 1190, 1195-97 (1974) (" $[\mathrm{H}]$ ospitalization itself interferes with privacy, since the patient cannot shield himself from constant observation by both his fellow patients and staff....").

$93 \mathrm{See}$ O'Connor v. Donaldson, 422 U.S. 563, 574-75 (1975).

94 Civil Commitment of the Mentally Ill, supra note 92, at 1197 ("Furthermore, patients in [state] hospitals risk brutality at the hands of their fellow residents and even their attendants ....").

95 Bruce J. Winick, Advance Directive Instruments for Those with Mental Illness, $51 \mathrm{U}$. MiAMI L. REV. 57, 68-69 (1996).

96 Id.

97 See HermanN, supra note 57, at 165; SLOBOGiN et al., supra note 47, at 806.

98 See infra note 99 and accompanying text.

99 Drummond v. City of Anaheim, 343 F.3d 1052, 1055 (2003).

100 Barry R. Furrow et al., Health Law $\S 6-11$ (2d ed. 2000); Cruzan v. Director, Miss. Dep't of Health, 497 U.S. 261, 269 (1990) (stating that the informed consent doctrine is firmly entrenched in American tort law). 
the informed consent doctrine in the mental health context is problematic ${ }^{101}$ because, during certain phases of their illnesses, psychiatric patients may lack the capacity required to provide informed consent. ${ }^{102}$ As the U.S. Supreme Court acknowledged in Zinermon v. Burch, mental illness creates special problems regarding informed consent. ${ }^{103}$ The nature of mental illness makes it foreseeable that a person needing treatment will be unable to understand forms he is being asked to sign and unable to make a knowing and voluntary decision concerning admission and treatment. ${ }^{104}$ For patients with mental illness, capacity is often a fluid concept. ${ }^{105}$ There are no clear legal guidelines as to what constitutes capacity. ${ }^{106}$ This fluidity negatively impacts their ability to obtain treatment because doctors are rightfully concerned about administering treatment without informed consent.

When a patient with no directive becomes incapacitated, the doctor may only administer treatment by following procedures for involuntary admission and treatment or obtaining consent from a court-appointed guardian if the court has found the patient legally incompetent. ${ }^{107}$ Without following such procedures, physicians who admit and treat a patient without informed consent are potentially liable for various torts, including the independent cause of action of lack of informed consent, ${ }^{108}$ assault, ${ }^{109}$ battery, ${ }^{110}$ negligence, and false imprisonment. ${ }^{111}$ Moreover, many state mental health codes allow patients to file claims against any person who violates the patient's rights by, for example, admitting an incapacitated patient under voluntary admission procedures. ${ }^{1 / 2}$ Patients of state operated facilities may also have federal civil rights claims under 42 U.S.C. $\S 1983$ (section 1983) for due process violations if the facility admitted and treated the patient without either obtaining informed consent or following procedures for involuntary admission and treatment. ${ }^{113}$

As a record of informed consent, the directive enables the physician to admit and treat the patient during episodes when capacity is in doubt. Directives therefore protect facilities and clinicians from liability for claims based on

101 SLOBOGIN ET AL., supra note 47, at 290.

102 Id.

103 Zinermon v. Burch, 49 US 113, 133 (1990).

104 Id.

105 Halverson, supra note 78, at 171 ("[E]ach patient has his or her own unique mental capabilities. In addition, a patient's mental status can fluctuate in any given day, week, month or year.").

106 Id. ("[T]here is no universal definition or method of determining competency.").

107 SLOBOGIN ET AL., supra note 47, at 290.

108 See, e.g., McCroskey v. University of Tennessee, 1995 WL 329133 at *4 (Tenn. Ct. App. 1995); Leach v. Shapiro, 469 N.E.2d 1047, 1052 (Ohio Ct. App. 1984).

109 Coyle, supra note 48 , at $\$ 25$.

110 See, e.g., Allore v. Flower Hosp., 699 N.E.2d 560, 564 (Ohio Ct. App. 1997); Gragg v. Calandra, 696 N.E.2d 1282, 1286 (IIl. App. Ct. 1998).

111 Coyle, supra note 48 , at $\$ 24$.

112 See, e.g., FLA. STAT. $\S 394.459(8)$ (b) (2013).

113 See, e.g., Zinermon v. Burch, 494 U.S. 113, 113 (1990). 
admitting and treating a patient without informed consent. The directive allows the doctor to treat a psychotic patient who does not meet involuntary commitment criteria. ${ }^{114}$ Moreover, the Uniform Act and state mental health directive statutes provide immunity from civil or criminal liability or from discipline for unprofessional conduct for clinicians and facilities that administer treatment pursuant to a directive. ${ }^{115}$

Zinermon v. Burch ${ }^{116}$ illustrates how directives might protect facilities and doctors from liability. Police found Burch, bruised, bloodied, and disoriented, wandering along a highway and transported him to a private facility designated by Florida to receive mentally ill patients. ${ }^{117}$ Staff evaluation indicated that Burch was psychotic. ${ }^{118}$ In this condition, he signed forms consenting to voluntary admission. ${ }^{119} \mathrm{He}$ remained in the facility for three days, was diagnosed with paranoid schizophrenia, and was administered psychotropic medication. ${ }^{120}$ Staff determined he needed longer-term stabilization and referred him to a state psychiatric hospital. ${ }^{121}$ There, he again signed forms requesting voluntary admission and treatment even though the report of the clinician at the state hospital asserted Burch remained psychotic. ${ }^{122}$ Clerks simply had Burch execute voluntary admission forms, and the facility considered him a voluntary patient. ${ }^{123}$ He remained at the state hospital for five months. ${ }^{124}$ During that time, he did not have benefit of counsel. ${ }^{125}$ No hearing was held where he could challenge his admission and treatment. ${ }^{126}$

After discharge, Burch filed a section 1983 claim against doctors, administrators, and staff at the state hospital. ${ }^{127} \mathrm{He}$ alleged they deprived him of liberty without due process by admitting him as a voluntary patient when they knew or should have known he lacked capacity. ${ }^{128}$ Florida law prohibited voluntary admission of an incapacitated patient. ${ }^{129}$ However, Florida failed to require a capacity determination in the course of voluntary admission. ${ }^{130}$ No one

114 See Elizabeth A. Rosenfeld, Mental Health Advance Directives: A False Sense of Autonomy for the Nation's Aging Population, 9 ELDER L.J. 53, 59-60 (2001).

115 UHCDA $\S 9($ a)(3); see, e.g., Wash. Rev. Code $\S 71.32 .170$ (2013) (granting providers immunity for following a directive in good faith and without negligence).

116494 U.S. 113 (1990).

117 Id. at 118 .

118 Id.

119 Id.

120 Id.

$121 \mathrm{Id}$. at $118-19$.

$122 \mathrm{Id}$. at $119-20$.

123 Id. at 134 .

124 Id. at 120.

125 Id. at 121 .

$126 \mathrm{Id}$. at 120.

$127 \mathrm{Id}$. at $114-15$.

128 Id. at 121 n.3.

$129 \mathrm{Id}$. at 135 .

$130 \mathrm{Id}$. at $150-51$. 
evaluated Burch to determine whether he had capacity to provide informed consent. ${ }^{131}$ Burch argued staff should have provided him procedural safeguards required by the Due Process Clause and Florida law for involuntary admission. ${ }^{132}$ The Supreme Court did not rule on the merits of the section 1983 claim but held it was justiciable. ${ }^{133}$ Exploration of the Court's analysis of procedural due process case law is outside the scope of this Article. ${ }^{134}$ However, the Court's discussion sheds light on the value of mental health directives. The Court stated that even if facilities are usually justified in taking at face value a person's request for admission for medical treatment, they might not be justified in doing so without further inquiry as to a mentally ill person's request for treatment in a mental hospital. ${ }^{135}$ Many people with mental illness lack capacity to give informed consent but do not meet commitment criteria ${ }^{136}$ because they are not likely to injure themselves or others and are still able to care for their basic needs.

The Court discussed the involuntary commitment procedures necessary to prevent the confinement of mentally ill people who are harmless and can live safely outside the facility. ${ }^{137}$ Involuntary confinement of these harmless individuals would violate the Constitution. ${ }^{138}$ If Burch had had an involuntary commitment hearing, he might not have met commitment criteria. ${ }^{139}$ A patient willing to sign voluntary admission forms but lacking capacity to provide informed consent could not be relied on to protest his voluntary admission and demand adherence to involuntary placement procedures. ${ }^{140}$ Staff members were the only people able to ensure procedural protections before depriving Burch of his liberty by admitting him without his informed consent. ${ }^{141}$ The State may delegate to facility staff the power to admit patients, but the staff must provide constitutionally required procedural safeguards and should not escape liability when they fail to do so. ${ }^{142}$

If Burch had a directive of which the facility was aware, the parties might have avoided litigation. If he did not want to be admitted even when he was psychotic, his directive could have made his refusal clear. Staff would have realized voluntary admission was not an option. To admit and treat Burch, they had to adhere to involuntary placement procedures. On the other hand, if Burch wanted doctors to treat him when he was psychotic, his directive could have documented his informed consent, enabling the facility to "voluntarily" admit

131 Id. at 113 .

132 Id.

133 Id. at $149-51$.

$134 \mathrm{Id}$. at 117.

$135 \mathrm{Id}$. at $133 \mathrm{n} .18$.

136 Id. at 122.

137 Id. at $133-34$.

138 Id. (citing O'Connor v. Donaldson, 422 U.S. 563, 575 (1975)).

139 Id. at 134 .

140 Id. at 135 .

141 Id.

142 Id. 
and treat him. ${ }^{143}$ Modern advance directive statutes would provide immunity from civil or criminal liability for administering treatment pursuant to the directive. ${ }^{144}$

Zinermon illustrates that doctors can be punished if they admit and treat patients whose capacity is in question without following an "elaborate involuntary admission process." 145 As the Supreme Court acknowledged, a psychotic patient may not meet involuntary commitment criteria. ${ }^{146} \mathrm{~A}$ directive is the only way patients can obtain intervention during an episode that temporarily destroys capacity. If a patient in the midst of an episode has no directive, the facility cannot voluntarily admit and treat him because he lacks capacity. ${ }^{147}$ If the patient does not meet commitment criteria, even if he is psychotic, the facility cannot admit and treat him. ${ }^{148}$

Directives not only document informed consent, they potentially improve treatment. ${ }^{149}$ Research indicates that mental health directives provide doctors clinically useful information that can expedite and improve care ${ }^{150}$ For example, a patient who has experienced lithium toxicity may use her directive to notify doctors that administration of lithium could be dangerous. Moreover, the patient may use her directive to provide instructions for personal matters such as caring for pets in the event the patient is hospitalized. The comfort of knowing her pets will be safe may encourage the patient to voluntarily remain in the hospital for treatment until she is stable.

\section{Safeguard Rights to Refuse Treatment}

Courts have based a person's right to refuse medical treatment on various constitutional, statutory, and common law sources. For example, in Cruzan v. Missouri Department of Health, the U.S. Supreme Court recognized that a competent person has a liberty interest under the Due Process Clause in refusing unwanted medical treatment, including life-sustaining hydration and nutrition. ${ }^{151}$ Similarly, in Washington v. Harper, which involved involuntary medication of a mentally ill inmate, the U.S. Supreme Court recognized a significant liberty interest under the Due Process Clause in avoiding unwanted administration of antipsychotic medication. ${ }^{152}$ Other constitutional bases support the right to refuse

143 See supra Section I.C.

144 E.g., Haw. REv. Stat. $\S 327 \mathrm{G}-10$ (2013); see Sheetz, supra note 9, at 431.

145 Zinermon, 494 U.S. at 140 (O’Connor, J., dissenting); see also supra Section I.C.

146 Zinermon, 494 U.S. at 133.

147 Id. at 117; Perlin, supra note 85, at 118 (predicting that Zinermon would reduce voluntary admissions at state hospitals).

148 Zinermon, 494 U.S. at 133-34 (citing O'Connor v. Donaldson, 422 U.S. 563, 575 (1975)).

149 Miller, supra note 27, at 735-37.

150 Debra S. Srebnik et al., The Content and Clinical Utility of Psychiatric Advance Directives, 56 PSYCHIATRIC SERVICES 592 (2005).

151 Cruzan v. Director, Miss. Dep't of Health, 497 U.S. 261, 278-79 (1990).

152 Washington v. Harper, 494 U.S. 210, 221 (1990). 
treatment, including the "penumbral" right to privacy's protection of bodily integrity. Moreover, the common law doctrine of informed consent, ${ }^{153}$ state statutes, ${ }^{154}$ and state constitutions support a person's right to refuse mental health treatments. $^{155}$

The right to form a directive is implicit in the right to refuse treatment because a directive enables a person with capacity to prevent administration of unwanted treatment when the person lacks capacity. ${ }^{156}$ In re Rosa $M$. illustrates why directives help safeguard rights to refuse treatment. ${ }^{157}$ In that case, the director of a psychiatric hospital applied for an order authorizing electroconvulsive therapy (ECT) on an involuntarily committed patient. Rosa M.'s psychiatrist opined that Rosa M.'s mental illness required treatment that included ECT. However, Rosa M. lacked capacity to consent to ECT. State regulations required authorization from an immediate family member or a court order to administer ECT to a patient who lacked capacity to consent. When she had capacity, Rosa M. had executed a directive refusing ECT. This directive documented and therefore protected her right to refuse. ${ }^{158}$ The court held that absent an overriding state interest, the hospital was required to honor her competent rejection of ECT even after she had lost capacity. ${ }^{159}$

\section{Avoid Guardianship}

Guardianship can help people with mental illness obtain treatment during episodes that destroy the capacity necessary to provide informed consent. ${ }^{160}$ The guardianship process starts when the court receives a petition to determine the incompetency of the ward and appoint a guardian. ${ }^{161}$ Many states allow any interested person to initiate guardianship proceedings. ${ }^{162}$ If the court determines the person is incompetent, a hearing takes place to determine whether the person needs a guardian. ${ }^{163}$ If there is clear and convincing evidence of the need for a guardian, the court appoints one either to make all legal decisions for the ward or only specific types of decisions the ward is incompetent to make. ${ }^{164}$

One advantage of a mental health directive is its potential to help the

153 Cruzan, 497 U.S. at 277.

154 Id.

155 Id.; Michael Flaherty, Nonconsensual Treatment of Involuntarily Committed Mentally III Persons with Neuroleptic or Antipsychotic Drugs as Violative of State Constitutional Guarantee, in 74 A.L.R.4th 1099 (last updated Oct. 2013).

156 Sheetz, supra note 9, at 423.

157 In re Rosa M., 597 N.Y.S.2d 544 (1991).

$158 \mathrm{Id}$. at 545 .

159 Id.

160 HERMANN, supra note 57, at 214.

161 Id.

162 Id.

$163 \mathrm{Id}$. at 216.

164 Id. at 216-17. 
mentally ill avoid guardianship. ${ }^{165}$ People with mental illness often experience long periods of full capacity and are capable of governing their lives and treatment. ${ }^{166}$ Many patients do not want "any interested person"167 to initiate proceedings for a judge to find them incompetent and appoint a guardian to make their decisions. Incompetency adjudications, a form of deviance labeling, can have seriously detrimental societal consequences and cause significant psychological damage to the ward. ${ }^{168}$ Many patients would prefer to execute a directive in which they can appoint an agent they trust to make decisions in line with their values. ${ }^{169}$ While it may be difficult for a directive to address every situation that may arise, the patient can engage in ongoing dialogue with the agent to ensure the agent understands the patient's thoughts about treatment. ${ }^{170}$ If the directive fails to address an issue, the agent can make decisions in line with the patient's values ${ }^{171}$ and there will be no need for the court to appoint a guardian. ${ }^{172}$

Some psychiatrists have asserted that guardianship poses a danger of harming the patient's civil rights, autonomy, and independence. ${ }^{173}$ These psychiatrists advised that doctors should recommend guardianship cautiously, only as a last resort for patients who are severely incompetent. ${ }^{174}$ When the situation is less extreme, physicians should recommend other alternatives, such as mental health directives. ${ }^{175}$

The process of creating a directive gives the patient a sense of empowerment and encourages self-responsibility. ${ }^{176}$ The planning process is therapeutic because it provides patients opportunities to analyze the patterns of their illnesses and prevent crises. ${ }^{177}$ Studies indicate patients experience a high level of satisfaction with intervention administered pursuant to a mental health directive. ${ }^{178}$

165 See Winick, supra note 95 , at 84.

166 Miller, supra note 27, at 731; Sheetz, supra note 9, at 404; see, e.g., AM. PsYchiatriC Ass'N , Diagnostic and Statistical Manual of Mental Disorders 123-39 (5th ed. 2013) [hereinafter DSM-V] (explaining that bipolar disorder is episodic); TERRI ChENEY, MANIC: A MEMOIR (2008).

167 See HERMANN, supra note 57, at 214.

168 Miller, supra note 27 , at 736 ; Winick, supra note 95 , at 84 .

169 Winick, supra note 95 , at 85 .

$170 \mathrm{Id}$. at 82.

171 See Dunlap, supra note 14, at 348 (asserting that a hybrid directive may be the most effective way to effectuate the patient's desires).

172 See Winick, supra note 95 , at 85.

173 Yuval Melamed et al., Guardianship for the Severely Mentally Ill, 19 MED. \& L. 321, 325 (2000).

174 Id. at 325 .

$175 \mathrm{Id}$.

176 Sheetz, supra note 9 , at 406-07.

177 Winick, supra note 95 , at 81-82.

178 Eric B. Elbogen et al., Effectively Implementing Psychiatric Advance Directives to Promote Self-Determination of Treatment Among People with Mental Illness, 13 PsYCHOL. PuB. POL'Y \& L. 273, 275, 285 (2007) (reporting on a study revealing that subjects reported high satisfaction with facilitated, one-on-one directive intervention). 
Researchers theorize that patients with directives perceive treatment to be more self-determined because directives allow patients to actively co-author individualized mental-health crisis prevention plans. ${ }^{179}$

\section{Addressing Concerns About Ulysses Arrangements}

\section{Concerns}

Despite the benefits of Ulysses arrangements, the concept of a self-binding directive remains controversial. Detractors argue that Ulysses arrangements are paternalistic. ${ }^{180}$ This criticism is similar to concerns about parens patriae commitment which enables the state to intervene in a person's decisions for her benefit without regard to whether she presents a risk to others. ${ }^{181}$

Critics also argue Ulysses arrangements create opportunities for undue influence, abuse, and coercion by doctors and family. ${ }^{182}$ Mental illness has the potential to wreak havoc not only on the patient, but also on the patient's loved ones. There is a danger that family and treatment team members, desperate to conquer the patient's illness, will coerce the patient into forming a Ulysses arrangement that they will then use as a tool to intimidate the patient into complying with a treatment regimen. ${ }^{183}$

Opponents argue the Ulysses arrangement violates due process because it enables a doctor to forcibly hospitalize and treat a patient even when the patient does not meet commitment criteria. ${ }^{184}$ Moreover, unlike in the civil commitment context, doctors implement Ulysses arrangements without procedural protections such as an adjudicatory hearing. ${ }^{185}$

Scholars also express concern about the risk of unanticipated consequences due to a patient's change of heart or failure to foresee all contingencies. ${ }^{186}$ Moreover, critics argue that consent provided in a Ulysses arrangement is not valid informed consent because it is not contemporaneous. ${ }^{187}$ They argue that informed consent is a continuing process in which doctors must obtain consent for each step of treatment. ${ }^{188}$ When doctors treat pursuant to a Ulysses arrangement, they rely on expired consent. ${ }^{189}$

179 Id. at 274-75.

180 See Rebecca S. Dresser, Ulysses and the Psychiatrists: A Legal and Policy Analysis of the Voluntary Commitment Contract, 16 HARV. C.R.-C.L. L. REv. 777, 785-91 (1982).

$181 \mathrm{Id}$. at 785 .

182 See id. at 852; Winick, supra note 95 , at 94.

183 See also Winick, supra note 95 , at 87 (stating some people may wish to have a directive refusing hospitalization made irrevocable to prevent family from pressuring them to revoke).

184 Dresser, supra note 180 , at 800.

$185 \mathrm{Id}$. at $813-14$.

186 See Winick, supra note 95 , at 88 .

187 Dresser, supra note 180 , at $830-32$.

$188 \mathrm{Id}$.

189 Id. 
Finally, detractors contend that to make Ulysses arrangements effective, patients must waive their privacy by notifying doctors, employers, family, and friends. ${ }^{190}$

\section{Response}

A distinction should be made between different types of paternalism. Ulysses arrangements are instruments of self-paternalism, not state-paternalism, because they implement a person's rational choices instead of her illness-induced choices. ${ }^{191}$ This self-paternalism respects patient autonomy by empowering the patient to direct her health care even during episodes that destroy the capacity necessary to provide informed consent. ${ }^{192}$ Depriving patients of the right to form Ulysses arrangements is itself a form of state-paternalism because it presumes to decide for the patient what is best for her.

It is true that doctors implement Ulysses arrangements without the procedural protections provided in civil commitment. However, the liberty deprivation involved in implementing a Ulysses arrangement is minimal compared to the deprivation of freedom involved in involuntary commitment, as discussed in Section I.C. When doctors implement a Ulysses arrangement, they follow a patient's advance written instructions. ${ }^{193}$ Involuntarily committed patients do not provide advance consent. Because implementation of a Ulysses arrangement involves hospitalizing a patient despite her contemporaneous objections, the enabling statute should provide procedural protections. ${ }^{194}$ The model provisions provide such protections because they: (1) limit self-binding hospitalization to three weeks, ${ }^{195}$ (2) require doctors to heed treatment refusals from patients with capacity, (3) require express written consent before administering psychotropic medication in contravention of illness-induced objections, (4) prohibit Ulysses arrangements for ECT and psychosurgery, and (5) allow patients to seek injunctive relief.

While Ulysses arrangements may create opportunities for abuse, the potential of the significantly more coercive environments of civil commitment and incarceration outweighs concerns of coercion from family and doctors. To protect against abuse, the enabling statute should impose safeguards to ensure patients form Ulysses arrangements voluntarily and doctors implement Ulysses arrangements in strict compliance with patient instructions. A patient with capacity should always be able to revoke her Ulysses arrangement. ${ }^{196}$ This

$190 \mathrm{Id}$. at 851

$191 \mathrm{ld}$.

192 See Willigenburg and Belaere, supra note 8, at 395-96.

193 Roberto Cuca, Ulysses in Minnesota: First Steps Toward a Self-Binding Psychiatric Advance Directive Statute, 78 CORNELL L. REV. 1152, 1153 (1993).

$194 \mathrm{Id}$. at $1154,1182-85$.

195 See Dresser, supra note 180 , at $781 \mathrm{n} .15$ (stating that three weeks is the suggested length). 196 VHA Report, supra note 10, at 9. 
Article's model provisions impose such safeguards including requirements for: (1) capacity determinations at the time of directive formation and implementation, (2) witnessing by multiple disinterested people, and (3) review and approval by two psychiatrists before administering treatment pursuant to a Ulysses arrangement.

To address concerns about unanticipated contingencies, patients and doctors should engage in ongoing dialogue and update the directive to ensure it remains current. ${ }^{197}$ The directive might also use broad language to enable doctors to administer the most therapeutic treatment. For example, a directive could consent to psychiatric medication generally, rather than specifying the particular medication. Like this Article's model, the enabling statute should grant patients the right to designate an agent who can implement the patient's wishes when unforeseen contingencies occur. Moreover, the model provisions provide for automatic expiration of Ulysses arrangements every two years. This mechanism helps ensure the Ulysses arrangement continues to represent the patient's wishes.

Although informed consent provided through a Ulysses arrangement is admittedly not truly contemporaneous, if patients are unable to form Ulysses arrangements, they become victims of their illnesses. When an episode causes them to refuse treatment, they cannot obtain intervention until they are deemed dangerous as defined by the state commitment statute. ${ }^{198}$ The Ulysses arrangement empowers the patient to determine her care when she lacks capacity to provide informed consent. ${ }^{199}$ Informed consent in the directive is valid because Ulysses arrangements are only appropriate for patients who have already experienced previous episodes and responded to treatment. ${ }^{200}$ Mental illnesses often follow a pattern that enables the patient and the doctor to predict the intervention necessary to address future episodes. ${ }^{201}$ Moreover, automatic expiration of Ulysses arrangements ensures the patient provided consent relatively recently. This will be discussed in Section II.E.

The criticism that Ulysses arrangements destroy privacy, like the others, presumes to weigh the benefits and risks of Ulysses arrangements for the patient. Acute episodes damage patients' lives and health. Patients should be able to decide that preventing future humiliating psychotic episodes that compromise their privacy justifies disclosing the Ulysses arrangement to their inner circles.

\section{ANALYSIS OF THE UNIFORM ACT AND STATE STATUTES}

Part II explains key provisions of the Uniform Act and state advance

197 Winick, supra note 95 , at $81-86$.

198 Cuca, supra note 193, at 1152.

199 Id. at 1153.

200 Id.; Dresser, supra note 180, at 800-01 (stating that confinement based on a Ulysses arrangement would allow for treatment that had been successful for the patient's past episodes).

$201 \mathrm{Id}$. at 847-51 (asserting that it would not respect patient liberty to permit enforcement of Ulysses arrangements where there is a high likelihood of predictive error). 
directive statutes. It illustrates that the Uniform Act, with its focus on end-of-life, ignores the needs of people with mental illness. For example, the Uniform Act: (1) does not empower patients to form Ulysses arrangements; (2) dispenses with execution requirements which protect against abuse; (3) fails to provide guidance on advance consent to common mental health treatments; (4) develops an automatic surrogate selection system which exposes mental health patients to undue risks; and (5) provides a template which is inappropriate in the mental health context. In addition, this Part explains how key provisions of state advance directive statutes fail to empower people with mental illness.

\section{A. Specialized Statute or One Size Fits All Approach?}

Before critiquing the Uniform Act, it is necessary to describe its primary purpose and a few of its key provisions. The Uniform Act, approved in 1993, strives to pave a health care decision-making superhighway. ${ }^{202}$ The doctrine of informed consent gives people with capacity the right to determine their treatment. ${ }^{203}$ When patients lack capacity, they need a mechanism through which to exercise control over their care. The Uniform Act provides this mechanism. It allows an individual with capacity to give oral or written instructions to a provider. ${ }^{204}$ These instructions remain in force even after the person loses capacity. ${ }^{205}$ The patient may also execute a written power of attorney for health care that authorizes an agent to make health care decisions when the patient lacks capacity. ${ }^{206}$ Moreover, a patient may orally designate a surrogate decisionmaker. ${ }^{207}$ For patients who fail to plan, the Uniform Act sets forth a system for automatically selecting a surrogate. ${ }^{208}$ The surrogate is bound by the patient's instructions or known wishes. ${ }^{209}$ When there are none, the surrogate must act in the patient's best interests. ${ }^{210}$

Only nine states ${ }^{211}$ have adopted the Uniform Act, likely because most states do not want to revisit their existing advance health care planning legislation just to make small improvements. ${ }^{212}$ Probably because mental illness planning implicates different issues than end-of-life planning, half of the states enacted

202 Sabatino, supra note 2, at 1238.

203 See supra Part I.C.

204 UHCDA $§ 2$.

205 Id. $\S 2$ (b), 7 (d).

206 Id. $\S 2$.

207 Id. $\S 5(\mathrm{~b})$.

208 Id.

209 Id. $\S \S 2(\mathrm{e}), 5(\mathrm{f})$.

$210 I d . \S \S 2(\mathrm{e}), 5(\mathrm{f})$.

211 See Ala. STat. $\$ 22-8$ A-1 to 22-8A-13 (2013); Alaska Stat. $\$ 13.52 .010-.52 .395$ (2013); Cal. Prob. Code $\S \S 4670-4743$ (2013); Del. Code ANN. tit. 16, $\S \S 2501-2518$ (2013); Haw. Rev. Stat. § 327E-1 to -16 (2013); ME. Rev. Stat. tit. 18-A, §§ 5-801 to 5-817 (2013); Miss. Code ANN. $\S 41-41-201$ to -229 (2013); N.M. STAT. ANN. § 24-7A-1 to -18 (2013); WYO. STAT. ANN. §35-22-401 to 35-22-416 (2013); see also Stith, supra note 2, at 40 n.l.

212 English, supra note 31 , at 19. 
separate mental health directive statutes. ${ }^{213}$ Generic directive statutes govern mental health directives in the remaining states. ${ }^{214}$ The Uniform Act is a model generic directive statute because it is not a specialized mental health directive statute. Instead, it purports to govern all advance health care planning, for both physical and mental illness. ${ }^{215}$ Generic directive statutes focus on end-of-life issues. For example, Florida has no separate mental health directive statute. ${ }^{216}$ The legislative findings of Florida's generic directive statute address end-of-life and palliative care but fail to mention psychotropic medication or ECT. ${ }^{217}$ Similarly, the recommended statutory forms in Illinois, Wisconsin, and Alaska for health care instructions make the instructions effective when the physician determines the patient has a terminal condition or is in a persistent vegetative state. ${ }^{218}$ This provision is inappropriate for patients who need their mental health directives to take effect when they lose capacity due to an acute episode. Moreover, the provision is potentially confusing and upsetting for otherwise healthy paticnts with mental illness. Having to confront emotionally charged endof-life issues at the same time as a mental health patient plans for the next episode might be disturbing for an already vulnerable patient.

The Uniform Act and state generic directive statutes created for end-of-life situations fail to address issues people with mental illness frequently face. This void burdens patients and hospitals with unnecessary litigation. In Cohen $v$. Bolduc, ${ }^{219}$ litigation escalated to the level of the state Supreme Court. Because Massachusetts had no mental health directive statute, the Massachusetts Supreme Court had to address whether the state general health care proxy statute authorized an agent to commit a principal to a mental health facility. ${ }^{220}$ The patient's proxy was activated in the summer of $2000 .{ }^{221}$ The Massachusetts Supreme Court did not issue its decision until January of $2002 .{ }^{222}$ Undoubtedly, the patient, her family, and her hospital wasted time and incurred unnecessary expense and emotional strain when the parties had to bring their case all the way to the state Supreme Court to resolve an avoidable situation. Of course, enacting a mental health directive statute will not obviate litigation. However, when mental health questions arise, courts will have the benefit of legislative

213 See Cohen v. Bolduc, 760 N.E.2d 714, 719 (Mass. 2002); VHA Report, supra note 10, at 3, 14-15 (listing Arizona, Hawaii, Idaho, Illinois, Indiana, Kentucky, Louisiana, Maine, Maryland, Michigan, Minnesota, Montana, New Jersey, New Mexico, North Carolina, Ohio, Oklahoma, Oregon, Pennsylvania, South Dakota, Tennessee, Texas, Utah, Washington, and Wyoming).

214 See VHA Report, supra note 10 , at 3.

215 UHCDA $\S 1(5)$.

216 FLA. STAT. $\S \S 765.101-.205$ (2013).

217 Id. $\S 765.102$ (2013).

218 See VHA Report, supra note 10, at 3; ALASKa STAT. $\$ 13.52 .010$ (2013); 755 ILL. ComP.

STAT. $\$ 43 / 5(2013)$; WIS. STAT. $\$ 155.05$ (2013).

219760 N.E.2d 714, 719 (Mass. 2002).

$220 \mathrm{Id}$. at 715 .

$221 \mathrm{Id}$. at 716 .

$222 \mathrm{Id}$. at 714 . 
guidance. $^{223}$

When a court applies a generic directive statute in a mental health crisis, the court is in the untenable position of interpreting a law intended to address end-oflife care, not mental illness. For instance, in the Cohen case, the court had to decide whether commitment authority was implicit in the generic directive statutory scheme. ${ }^{224}$ The health care proxy statute defined "health care" to include any treatment, service or procedure to diagnose or treat the patient's physical or mental condition. ${ }^{225}$ From this reference to mental conditions, the court decided that the legislature did not intend to limit the agent's authority. ${ }^{226}$ As Cohen acknowledged, the legislature had never addressed the commitment issue. ${ }^{227}$ The Court was forced to survey other states' mental health directive statutes, which were split as to whether an agent possessed commitment authority. ${ }^{228}$ Cohen looked to the Uniform Act, which only allows an agent or surrogate to commit if the principal expressly provided commitment authority in a written directive. ${ }^{229}$ Other state legislatures, whose statutory definitions of health care included treatment of mental conditions, decided that an agent did not have commitment authority. ${ }^{230}$

In a legislative vacuum, the Cohen court made a policy decision that express commitment authority is not required for an agent to commit the principal. ${ }^{231}$ Cohen made this policy decision despite the fact that several state advance directive statutes prohibit an agent from committing a principal. ${ }^{232}$ Reasonable lawmakers disagree on the issue. ${ }^{233}$ Cohen underscores the need for a model mental health directive statute for state elected officials to adopt, enabling elected lawmakers to give guidance on key mental health issues. The process of enacting a mental health directive statute requires the legislature to address issues implicated in advance planning for acute episodes. When the legislature considers the proposed legislation, it will review testimony from experts and stakeholders, including psychiatrists and patients. This process will enable the legislature to develop sound policy for the state. ${ }^{234}$

223 See infra Part III.

224 Cohen, 760 N.E.2d at $719-20$.

225 Id. at 720.

$226 \mathrm{ld}$.

227 Id. at 718 .

$228 \mathrm{Id}$. at $718-19$.

229 Id. at 718 n. 14 .

230 Id. at 718 n. 15 .

231 Id. at 721 .

232 Id. at 718.

233 ld.

234 See, e.g., Anderson, supra note 13, at 801 (exploring patient testimony before the Washington legislature when it considered the bill). 


\section{B. Revocation and Ulysses Arrangements}

\section{Requirements for a Ulysses Enabling Statute}

To empower patients to form Ulysses arrangements, the enabling statute must have a few key components. First, it must enable patients to choose to form a directive that is irrevocable during periods of incapacity. A patient who cannot form an irrevocable directive cannot enter a Ulysses arrangement. Because episodes often cause patients to refuse treatment and revoke their directives, irrevocable directives are necessary to enable patients to secure treatment despite contemporaneous refusals. ${ }^{235}$

However, allowing patients to form irrevocable directives does not, in and of itself, empower patients to form Ulysses arrangements. The enabling statute must set forth procedures for administering treatment in the face of contemporaneous objections. $^{236}$ Without a well-defined process and clear authority, a doctor typically will not force treatment on a refusing patient based only on the fact that her directive is irrevocable when she lacks capacity. Even with the typical statutory statement of provider immunity, doctors will be rightfully concerned about liability for unlawfully administering involuntary treatment.

Physician reluctance to treat in the face of contemporaneous objections is not the only concern. A more serious concern involves risks of coercion, undue influence, and fraud when doctors forcibly hospitalize and treat a patient even when the patient does not meet commitment criteria. ${ }^{237}$ The enabling statute must provide procedural protections to ensure that patients form Ulysses arrangements knowingly and voluntarily and that doctors implement the arrangements in strict accordance with patient instructions. ${ }^{238}$

\section{The Uniform Act Approach}

The Uniform Act does not empower patients to form Ulysses arrangements for several reasons. First, it does not allow patients to choose whether they can revoke their directives when they lack capacity. ${ }^{239}$ The revocation provision allows an individual to revoke the designation of an agent by a signed writing or by notifying her physician. ${ }^{240}$ Individuals may revoke at any time and in any manner that communicates intent to revoke portions of the directive that do not designate a surrogate, such as instructions. ${ }^{241}$ The revocation provision does not

235 Cuca, supra note 193, at 1173.

236 Id. at 1181-85.

237 Dresser, supra note 180 , at 800.

238 Cuca, supra note 193, at 1154.

239 UHCDA $\S \S 3,11$.

240 Id. § 3(a).

241 Id. $\S 3(\mathrm{~b})$. 
expressly require capacity to revoke. ${ }^{242}$ However, the Uniform Act capacity provision states "an individual is presumed to have capacity to make a healthcare decision, to give or revoke an advance health-care directive, and to designate or disqualify a surrogate."243 The commentary explains that this is a rebuttable presumption. ${ }^{244}$ These provisions are subject to two different interpretations, neither of which empowers patients to form Ulysses arrangements.

Under the first interpretation, the Uniform Act precludes patients from forming irrevocable directives. This is because it does not expressly require capacity to revoke and does not allow patients to designate whether their directives are revocable during periods of incapacity. ${ }^{245}$ This might be why some states that implemented the Uniform Act amended the Act's language to expressly require capacity for revocation. ${ }^{246}$ For example, the New Mexico statute states that "an individual while having capacity may revoke."247 The New Mexico legislature recognized that if it wanted to require capacity for revocation, an amendment was necessary. If the Commissioners intended to require capacity for revocation or to give patients the choice, the Uniform Act would have done so expressly.

Comparison to state statutes that allow patients to choose supports the conclusion that the Uniform Act does not give patients the choice. For example, the Arizona statute states that "unless limited by the express authority in this document, a principal even if incapable, may revoke" her mental health directive. ${ }^{248}$ The Uniform Act does not contain such language. ${ }^{249}$ In other instances in which the Uniform Act provides patients a choice, it does so expressly. For example, the Uniform Act states that a directive becomes active when the patient lacks capacity unless the patient provides otherwise. ${ }^{250}$ The Uniform Act revocation provision does not contain such language. ${ }^{251}$ Therefore, pursuant to this first interpretation, the Uniform Act precludes patients from forming irrevocable directives.

However, there is another possible interpretation. Under this second interpretation, the Uniform Act requires capacity to revoke a directive. This alternative interpretation relies on the Uniform Act's rebuttable presumption of capacity to revoke the directive. ${ }^{252}$ Arguably, the rebuttable capacity presumption implies that only patients with capacity may revoke. If someone is able to rebut

242 See id. $\$ 3$.

243 Id. $\S 1 \mathrm{I}(\mathrm{b})$ (emphasis added).

244 Id. $\$ 11, \mathrm{cmt}$.

245 Id. $\S \S 3,11$.

246 ME. Rev. Stat. tit. 18-A, §5-803 (2013); N.M. STAT. §24-7A-3 (2013); Wyo. STAT. ANN. $\S 35-22-404(2013)$.

247 N.M. STAT. § 24-7A-3 (emphasis added).

248 ARIZ. REV. STAT. § 36-3285 (2013) (emphasis added).

$249 C f$. UHCDA $\S 3$.

250 Id. \& 2(c).

251 Cf. id. $\$ 3$.

$252 \mathrm{Id} . \S 11 \mathrm{cmt}$. 
the capacity presumption, the incapacitated patient will be prevented from revoking her directive. Under this interpretation, at least in theory, patients may form irrevocable directives.

Even assuming the Uniform Act requires capacity for revocation, it does not empower patients to form Ulysses arrangements for two reasons. First, the Commissioners did not describe how to rebut the capacity presumption. ${ }^{253}$ This omission may be why some states that implemented the Uniform Act added instructions. ${ }^{254}$ For example, Maine added the following statement: "This presumption may be rebutted by a determination by the individual's primary physician or by a court of competent jurisdiction." 255 Without guidance like this, it is unlikely anyone will try, much less succeed in rebutting the capacity presumption. The patient's revocation will stand even if it was induced by an episode. This is especially true because one purpose of the Uniform Act is to place health care decisions in the hands of the patient, the family, and providers, not the courts. ${ }^{256}$ Rebutting the capacity presumption would likely involve court intervention which the Commissioners sought to avoid. ${ }^{257}$ Even assuming a Uniform Act capacity requirement for revocation, the Commissioners' failure to provide guidance on rebutting the capacity presumption prevents patients from forming self-binding arrangements.

Even if one interprets the Uniform Act to require capacity to revoke, the Uniform Act does not empower people to form Ulysses arrangements for a second reason. It provides no process for administering treatment pursuant to an irrevocable directive in the face of patient refusals. It does not set forth clear authority and procedural protections necessary to overcome physician reluctance to treat in the face of illness-induced refusals and to protect patients from coercion and abuse.

\section{States' Approaches}

A majority of all states allow the principal to revoke a generic directive at any time, even if she has lost capacity. ${ }^{258}$ However, most states with mental health directive statutes only allow a patient with capacity to revoke a mental

253 See id.

254 See, e.g., ME. REv. STAT. tit.18-A, §5-811 (2013); N.M. STAT. §24-7A-11 (2013); Wro. STAT. ANN. §35-22-412 (2013).

255 ME. Rev. STAT. tit. 18-A, § 5-811.

256 See Barry Furrow et al., Health law, Cases, Materials, and Problems 814 (7th ed. abr. 2013).

257 See supra note 254 and accompanying text; UHCDA $\$ 6 \mathrm{cmt}$. (stating that courts have no particular expertise with respect to healthcare decision-making and court involvement causes delays).

258 See VHA Report, supra note 10, at 9 (noting that in 36 out of 50 states, incapacitated patients may revoke a generic directive). 
health directive. ${ }^{259}$

Patients should not be forced to form irrevocable directives. The majority of states with separate mental health directive statutes reinforce the stigma of mental illness when they do not allow patients to choose whether to make their directives revocable during periods of incapacity. ${ }^{260}$ The rationale for prohibiting incapacitated patients from revoking mental health directives is that preferences articulated in a written directive more likely reflect the authentic values of the patient than choices made when the patient is incapacitated. ${ }^{261}$ The rationale is based on the premise that restricted revocation during periods of incapacity best serves patient autonomy because it respects a patient's choices made when she was able to thoroughly consider the risks and benefits of treatment options. ${ }^{262}$ This premise applies equally for generic directives as it does for mental health directives. Therefore, there is no policy reason to restrict revocation of mental health directives if the state does not restrict revocation of generic directives, and most states do not. ${ }^{263}$

Restricted revocation only for mental health directives undermines parity for mental health care. In one study, almost half of surveyed patients indicated they wanted authority to revoke their mental health directives during periods of incapacity. ${ }^{264}$ In states that do not allow incapacitated patients to revoke their mental health directives, patients only have the power to create self-binding directives. ${ }^{265}$ They cannot create individualized mental health care plans. One of the Commissioners' goals was to encourage patients to form advance directives. ${ }^{266}$ Patients have greater autonomy if they provide advance instructions and designate agents who understand their preferences. ${ }^{267}$ Patients who want the power to revoke their mental health directives when they lack capacity may refrain from advance planning if their only option is to form an irrevocable directive.

Typical mental health directive statutes do not empower patients to form Ulysses arrangements because they fail to set forth a process for administering treatment in the face of illness-induced refusals. ${ }^{268}$ The typical statute merely requires capacity for revocation and provides immunity to physicians who follow

$259 \mathrm{Id}$. (noting that 18 out of 25 states with mental health directive statutes only allow revocation from patients with capacity).

260 See id. at 9; Cuca, supra note 193, at 1162-63; Gallagher, supra note 6, at 778; Srebnik et al., supra note 150 , at 592 .

261 VHA Report, supra note 10, at 9; Cuca, supra note 193, at 1162-63.

262 VHA Report, supra note 10 , at 9.

263 Gallagher, supra note 6, at 778; VHA Report, supra note 10, at 9.

264 Srebnik et al., supra note 150 , at 592.

265 See Dresser, supra note 180, at 781; Sabatino, supra note 2.

266 Sabatino, supra note 2, at 1238-39.

267 Id. at 1239.

268 Dresser, supra note 180 , at 781 (Several safeguards would have to be in place for a Ulysses arrangement.). 
the directive. ${ }^{269}$ This is insufficient to enable physicians to forcibly hospitalize and treat patients who do not meet commitment criteria. Physicians will be legitimately fearful of liability for administering involuntary treatment. A clear process with safeguards against abuse helps address concerns that family and providers will coerce patients into forming Ulysses arrangements that they will use to force treatment on the patient. Patients should only enter Ulysses arrangements voluntarily and knowingly. Therefore, such arrangements are not appropriate for patients deprived of the right to choose whether they can revoke their directives when they lack capacity.

\section{Washington's Approach}

Washington has a unique approach that provides instructions on implementation of an irrevocable directive. When a principal's mental health directive remains irrevocable during incapacity and consents to inpatient mental health treatment, but the principal refuses admission, the facility may admit the patient despite illness-induced refusals. ${ }^{270}$ There are strict criteria for such admission. ${ }^{271}$ First, one doctor in conjunction with another ${ }^{272}$ must determine whether the principal lacks capacity. The Washington statute does not address whether a principal's refusal of admission in contravention of express instructions in her directive supports a determination of incapacity. ${ }^{273}$ This is a failure because many mental illnesses can induce people to refuse admission and treatment. ${ }^{274}$ The directive provides clear evidence that the patient, when she had capacity, requested admission and treatment. Second, the doctor must obtain the informed consent of the principal's agent if one is designated. ${ }^{275}$ Third, after evaluation, the doctor must determine and make a written finding that the principal needs inpatient evaluation or treatment that cannot be accomplished in a less restrictive setting. ${ }^{276}$ Fourth, the doctor must document in the patient's medical record a summary of findings and recommendations. ${ }^{277}$

If the doctor determines the principal has capacity, the principal may only be

269 See, e.g., HAW. REV. STAT. $\S 327 \mathrm{G}-4$ (2013) (merely stating that capacity is required to revoke); 755 ILL. COMP. STAT. $\$ 43 / 5$ (2013); Sheetz, supra note 9, at 431 (Many statutes grant immunity for providers who make good faith efforts to comply with directives.).

270 WASH. REV. CODE $§ 71.32 .140$ (2013).

271 Id. $\$ 71.32 .140(2)$.

272 Id. $\S 71.32 .140$ (2)(a)-(3). The statute requires a physician or psychiatric registered nurse practitioner, in conjunction with another health care provider, to make the incapacity determination. If the admitting clinician is not a psychiatrist/psychiatric advanced registered nurse practitioner, a mental health professional shall assess the principal within 24 hours to determine continued need for inpatient evaluation or treatment.

273 Id. § 71.32.140.

274 See supra note 10 and accompanying text.

275 WASH. REV. CODE $§ 71.32 .140(2)(b)$.

276 Id. $\$ 71.32 .140$ (2)(c).

277 Id. $\$ 71.32 .140(2)(\mathrm{d})$. 
admitted or remain in inpatient treatment if the principal consents or is detained under involuntary commitment law. ${ }^{278}$ If two doctors determine that the principal lacks capacity and the principal continues to refuse admission, the principal may seek injunctive relief. ${ }^{279}$ The facility may retain the patient for up to 14 days, and only for the amount of time that she consented to inpatient treatment in her directive. At that point, the facility must discharge the patient unless she regains capacity and consents to further treatment or is detained under involuntary commitment law. ${ }^{280}$

The incapacitated principal's instructions in her directive control her treatment with one significant exception. ${ }^{281}$ Even if the principal's irrevocable directive consents to inpatient treatment despite illness-induced refusals, the facility shall discharge the principal if she "takes actions demonstrating a desire to be discharged, in addition to making statements requesting to be discharged."282 The facility shall not use restraint in any way to prevent discharge. ${ }^{283}$ This limitation essentially prevents patients from entering Ulysses arrangements. ${ }^{284}$

Even the Washington approach, noted for its progressive support of patient empowerment, ${ }^{285}$ falls short of authorizing Ulysses arrangements. First, it requires a facility to discharge an incapacitated patient who takes action and makes statements demonstrating the desire to be discharged, even if discharge contravenes the patient's irrevocable directive. ${ }^{286}$ The following illustrates why this prevents Ulysses arrangements.

A patient executes an irrevocable directive consenting to inpatient treatment that becomes active pursuant to its terms. His daughter drives him to a hospital where he refuses admission. The admitting psychiatrist follows the Washington protocol and determines that the patient lacks capacity and needs the inpatient treatment his directive describes. ${ }^{287}$ The mentally ill patient does not recognize that he is ill. He demands discharge through words and actions. Psychiatrists determine that although the patient lacks capacity, he fails to meet involuntary commitment criteria. Left untreated, his mental illness will likely escalate to

278 Id. $\S 71.32 .140(4)(\mathrm{a})$.

279 Id. $\$ 71.32 .140(4)(\mathrm{d})$.

280 Id. $\$ 71.32 .140(5)$.

281 Id. $\$ 71.32 .140(6)(\mathrm{b})$.

282 Id.

283 Id.

284 See id. (providing that because this is a voluntary admission, a patient who takes action to leave and demands discharge must be discharged unless she meets involuntary commitment criteria but failing to explain why the patient's illness-induced demands override her consent in her directive).

285 See Sheetz, supra note 9, at 401 (stating that Washington authorizes Ulysses directives and advocating for other states to adopt similar provisions).

286 WASH REV. CODE $§ 71.32 .140$ (6)(b).

287 Id. $\S 71.32 .140(2)$. 
psychosis. ${ }^{288}$ Despite this inevitability, Washington requires discharge. ${ }^{289}$

Second, Washington fails to assist doctors in their assessment of patient capacity when a principal's illness-induced refusals contradict the patient's directive. ${ }^{290}$ When a principal arrives at a facility but refuses admission because of an episode, Washington requires a capacity assessment. ${ }^{291}$ If doctors determine the principal lacks capacity, they may admit the principal only if they follow strict protocols. ${ }^{292}$ If the principal has capacity, doctors must discharge the principal unless the principal consents to inpatient treatment. ${ }^{293}$ The Washington statute fails to recognize that a person who refuses care requested in her irrevocable directive necessarily exhibits substantial evidence of incapacity.

A person cannot have capacity if he does not understand the significant benefits of proposed treatment. Acute episodes can destroy insight and cause patients to refuse intervention. ${ }^{294}$ When a patient's irrevocable directive consents to treatment that the patient refuses when he arrives at the hospital, the refusal itself is evidence of incapacity. In this way, the Washington statute ignores several factors that make doctors reluctant to admit patients whose illnesses cause them to refuse treatment. First, only a small percentage of patients with mental illness execute mental health directives. ${ }^{295}$ Therefore, most psychiatrists have little experience implementing directives generally, much less Ulysses arrangements. Second, psychiatrists are very familiar with the strict criteria for involuntary admission and treatment. Unless Washington instructs otherwise, doctors will likely automatically apply this strict criteria. Third, because capacity is fluid, capacity determinations are not black and white decisions. When in doubt, doctors will likely err on the side of caution and discharge patients whose illnesses cause treatment refusals regardless of consent to treatment in an irrevocable directive. ${ }^{296}$ This caution prevents necessary intervention. Honoring a patient's consent to early intervention in an irrevocable directive not only respects patient autonomy, it could potentially save the patient's life.

288 See supra note 13 and accompanying text.

289 WASH REV. CODE $\S 71.32 .140(6)(b)$.

290 Id. § 71.32.140; see also id. § 71.32.110.

291 Id. $\S 71.32 .140(2)$.

292 Id.

293 Id. § 71.32.140(4)(a).

294 See supra note 10 and accompanying text.

295 See Maria J. O'Connell \& Catherine H. Stein, Psychiatric Advance Directives: Perspectives of Community Stakeholders, 32 Admin. \& Pol'y Mental Health 241, 244 (2005) (Only $6.8 \%$ of people with schizophrenia surveyed had a mental health directive.); Jeffrey Swanson et al., Psychiatric Advance Directives Among Public Mental Health Consumers in Five U.S. Cities: Prevalence, Demand, and Correlates, 34 J. AM. ACAD. PsyChIATRY \& L. 43, 54 (2006) (finding that between 4 and $13 \%$ of mental health patients surveyed had directives).

296 See supra notes 107-113 and accompanying text. 


\section{Execution}

\section{The Uniform Act's Minimal Execution Requirements}

Under the Uniform Act, an "individual instruction" is the principal's directions about her health care. ${ }^{297}$ Oral instructions are valid. ${ }^{298}$ The patient's physician need only record the oral instructions in the principal's medical record. ${ }^{299}$ A patient may issue written instructions without any witnesses, notarization, or mandatory form or language. ${ }^{300}$

The Uniform Act permits three types of proxies to make health care decisions for patients who lack capacity: surrogates, guardians, and agents. ${ }^{301} \mathrm{~A}$ principal's designation of an agent (a power of attorney for health care) must be in a signed writing. ${ }^{302}$ The only people who may not be agents are owners, operators, or employees of residential long-term health care institutions where the principal receives care, unless they are related to the principal. ${ }^{303}$ Designation of an agent need not be witnessed or notarized. ${ }^{304} \mathrm{~A}$ surrogate is an individual authorized to make the principal's health care decisions when the principal lacks capacity, and no agent or guardian has been designated or is available. ${ }^{305} \mathrm{~A}$ patient may select a surrogate orally by personally informing her doctor. ${ }^{306}$

A comparison with state advance directive statutes is useful to illustrate that many legislatures consider execution requirements to be useful protections against abuse. Every state that implemented the Uniform Act imposed witnessing requirements for all directives, presumably to protect against fraud and coercion. $^{307}$ The need to protect against coercion in the context of mental health directives is arguably greater than the need for generic directives. Scholars and legislatures have recognized the potential risk of family and doctors using mental health directives as instruments to coerce patients to accept certain treatments. ${ }^{308}$ Patients with mental illness are especially vulnerable to coercion because they may perceive the threat of involuntary commitment or forced administration of

297 UHCDA $\S 1(9)$.

298 Id. $\S 2(\mathrm{a})$.

299 Id. $\S 7$ (b); Sabatino, supra note 2, at 1243.

300 UHCDA $\S 2$.

301 Id. § 1; see Sabatino, supra note 2, at 1242.

302 UHCDA $\S 2$ (b).

303 Id. $\S 2$ (b) \& cmt.

304 Id.

$305 I d . \S 5(\mathrm{a})$.

$306 I d$. \&5(b)

307 Charles P. Sabatino, The Evolution of Health Care Advance Planning Law and Policy, 88 MiLBank Q. 211, 217 (2010).

308 Dunlap, supra note 14 , at 378 (noting that states enacted penalties against people who coerce a patient into or out of executing a mental health directive); Lester J. Perling, Health Care Advance Directives: Implications for Florida Mental Health Patients, 48 U. MIAMI L. Rev. 193 (1993). 
medication. ${ }^{309}$ The potential for undue influence may be why almost all states with separate mental health directive statutes have included restrictions on who may serve as a witness. ${ }^{310}$ Several states prohibit members of a principal's family and treatment team members from serving as witnesses. ${ }^{311}$ Typically, witnesses must attest to certain observations such as that the principal executed the directive voluntarily. ${ }^{312}$

State statute approaches underscore the fact that protections against abuse are necessary. The Uniform Act's minimal execution requirements expose mental health patients to risks of undue influence, fraud, and coercion. Because the Uniform Act does not allow for Ulysses arrangements, this section criticizes the Uniform Act's minimal execution requirements for any mental health directive. Ensuring that there are robust protections against abuse is even more critical in the context of Ulysses arrangements. This is because there is a danger that family and providers will coerce the patient into forming a Ulysses arrangement and then use the arrangement as a tool to intimidate the patient to comply with a treatment regimen. ${ }^{313}$

\section{Elimination of Witnessing Requirements Poses Undue Risks}

The Uniform Law Commissioners' elimination of a witness requirement removes an important protection against undue influence, coercion, and fraud. ${ }^{314}$ Witness attestation that the principal showed identification or that the witness knew the principal and had no reason to suspect the principal executed the directive under undue influence or fraud helps ensure execution was voluntary. Moreover, the Commissioners should remove from the potential witness pool people who may have conflicts of interest. Allowing family and treatment team members, who often hold strong opinions about optimum treatments, to witness the directive presents unnecessary risks of coercion and undue influence. ${ }^{315}$ Agents should not serve as witnesses because they have the authority to make all

309 Bruce J. Winick, Outpatient Commitment: A Therapeutic Jurisprudence Analysis, 9 PsYCH. PuB. \& L. 107 (2003).

310 VHA Report, supra note 10 , at 5 (stating that concerns over coercion and undue influence caused all of the states with separate statutes except Montana to restrict who may serve as witnesses).

311 Id. (listing Arizona, Hawaii, Idaho, Illinois, Kentucky, Michigan, New Mexico, North Carolina, Oklahoma, Oregon, Pennsylvania, South Dakota, Tennessee, Texas, Utah, and Washington as excluding family members and all of the previously listed states in addition to Wyoming as excluding treatment team members).

312 Id. (stating most mental health directive statutes require witness attestation except Indiana, Maine, Maryland, Montana, and Washington).

313 Id.

314 Stith, supra note 2 , at $47-48$ ("The streamlined procedures appear to sacrifice safeguards for efficiency.").

315 VHA Report, supra note 10, at 5-6. 
health care decisions when the principal lacks capacity. ${ }^{316}$ Furthermore, agents should not witness the same instrument that gives them this power. ${ }^{317}$ People affiliated with health care facilities in which the principal receives treatment should not serve as witnesses because they have financial interests in administering care.

\section{Elimination of the Signed Writing Requirement Removes Safeguards}

The Uniform Act has been commended for permitting patients to orally designate surrogates and issue treatment instructions because this flexibility is practical and removes obstacles to advance health care planning. ${ }^{318}$ Most people do not create written directives, possibly because they do not like to think about death. When patients do issue instructions, they tend to do so informally. ${ }^{319}$ The typical patient may say, "If I lose capacity, my daughter should make decisions concerning my care.",320 The Uniform Act enforces oral instructions and designations of surrogates for this reason. ${ }^{321}$

This is why the Uniform Act's elimination of the signed writing requirement is another example of its focus on end-of-life circumstances, not episodic mental illness. For patients with mental illness, the risks posed by enforcing oral instructions and designations of surrogates do not justify the purported benefits. This is because oral instructions are less portable, more susceptible to fraud, and make physicians vulnerable to false accusations. Moreover, requiring a signed writing better ensures the patient has capacity when he forms a directive.

First, people with mental illness need portable instructions and designations of agents. Oral instructions are not as readily portable as a written directive. ${ }^{322}$ Patients often receive treatment for acute episodes in emergency rooms or in prison health clinics. ${ }^{323}$ Mental illness patients benefit from portable directives that can be followed wherever they receive treatment.

Second, oral instructions are less reliable and more susceptible to misinterpretation and fraud than written directives. Because mental illnesses are complicated, ${ }^{324}$ patient instructions in such cases are often nuanced. If a patient makes off-the-cuff remarks under the stress of an impending crisis, the Uniform Act grants the physician, who has financial interests in administering care and strong opinions about optimal treatments, the authority to record and therefore

316 UHCDA § $1(2)$.

317 Id.

318 See Sabatino, supra note 2, at 1244-45.

319 FURRow, supra note 100, at 849 (stating that only 10-25\% of Americans have documented end-of-life choices or appointed an agent).

320 Sabatino, supra note 2, at 1244-45.

321 Id.

322 Sabatino, supra note 2, at 1243.

323 See supra note 29.

324 DSM-V, supra note 166. 
interpret these inherently unreliable oral remarks. ${ }^{325}$ Enforcing oral instructions risks misinterpretation of patient wishes. Moreover, it creates opportunities for health care fraud. Mental health care is particularly susceptible to fraud because: (1) strict patient confidentiality makes abuse hard to discover; (2) the practice of mental health medicine is highly subjective; and (3) mental health patients are often less able to chronicle their treatment than other patients. ${ }^{326}$ Therefore, in the mental health sector, enforcing oral instructions recorded by the patient's physician increases opportunities for fraud and abuse. ${ }^{327}$

Third, a signed writing requirement protects doctors from fraudulent claims that they administered treatment without informed consent. The written, signed directive documents informed consent to all treatment administered pursuant to its terms. A physician's notes recording a patient's oral remarks may not provide sufficient evidence of informed consent if the patient claims she never consented.

Finally, determining the precise moment an episode causes a person to lose capacity requircd to issue binding oral instructions is difficult. There is a concern, for example, that a patient with bipolar disorder will utter oral instructions to his doctor when he is hypomanic but technically has capacity. During some episodes of mental illness, patients refuse treatment even though they would have requested treatment if they were not altered by an episode ${ }^{328}$ Moreover, acute episodes may alter a person's judgment in other ways. A bipolar patient when hypomanic may associate with people with whom he would not associate when he was well and ask one of these strangers to be his surrogate. Requiring a written directive better ensures that patients have full capacity when they issue instructions or designate an agent.

\section{The Capacity Presumption and Definition}

The Uniform Act defines capacity as an individual's ability to understand the significant benefits, risks, and alternatives to proposed health care and to make and communicate health care decisions. ${ }^{329}$ There is a rebuttable presumption of capacity. ${ }^{330}$ No clinician determination of capacity is necessary to create a directive. ${ }^{331}$ The Uniform Act's definition of capacity is similar to the definition of capacity used in many mental health directive statutes. ${ }^{332}$ Most states' statutes, like the Uniform Act, have a statutory presumption of capacity to execute any

325 UHCDA $\S 7($ b).

326 See Pamela H. Bucy, Health Care Fraud and the False Claims Act, ABA CTR. Continuing Legal Educ. NaT'L InST., Nov. 19-20, 1998, at *9 (1998), available at N98CFCB ABA-LGLED E-1 (Westlaw); Rosenfeld, supra note 114, at 77.

327 Id.

328 See supra note 10 and accompanying text.

329 UHCDA § $1(3)$.

330 Id. $\S 11(\mathrm{~b})$.

$331 \mathrm{Id}$.

332 See, e.g., HAW. REV. STAT. $\S \S 327 \mathrm{G}-2,-5$ (2013). 
directive, including a mental health directive. ${ }^{333}$ However, in Louisiana, an individual wishing to create a mental health directive, but not a generic directive, must obtain a clinician's written attestation that she examined the principal and determined the principal had capacity. ${ }^{334}$

Requiring a physician attestation of patient capacity to form any mental health directive ${ }^{335}$ stigmatizes people with mental illness and creates an unnecessary administrative obstacle to advance planning. When free from the influence of an episode, many people with mental illness are no less able to make rational treatment choices than people who do not have a mental illness. ${ }^{336}$ This is why the Commissioners' decision to use the same definition of capacity for the physical and the mental health contexts makes sense. ${ }^{337}$ Moreover, unlike Louisiana, the Commissioners wisely decided to presume that all patients have capacity to form a directive. That presumption is appropriately rebuttable because some patients lack capacity.

However, there are compelling reasons to require a capacity determination at the time a patient forms a Ulysses arrangement. Ulysses arrangements are instruments of self-paternalism. ${ }^{338}$ They respect patient autonomy by empowering the patient to direct her health care even during episodes that destroy capacity. ${ }^{339}$ It is essential that the patient has capacity when she forms a Ulysses arrangement. Critics worry that because mental illness often negatively affects loved ones, family may be prone to coerce the patient into forming the arrangement. ${ }^{340}$ A physician's attestation of the principal's capacity at the time of execution is necessary to ensure self-binding treatment is what the patient really wants.

\section{Activation}

To choose the best activation standard, it is necessary to identify the available options: (1) legal incompetence (used for guardianship proceedings), (2) decision-making capacity (used for informed consent), ${ }^{341}$ (3) dangerousness or severe disability (used for involuntary commitment), or (4) patient-designated activation. $^{342}$

333 Winick, supra note 95, at 68 n.39; Sheetz, supra note 9, at 413.

334 La. Rev. Stat. ANN. § 28:224 (2013); Sheetz, supra note 9, at 414.

335 See supra note 326 and accompanying text.

336 Sheetz, supra note 9, at 405.

337 UHCDA §1(3).

338 See Dresser, supra note 180 , at 851.

339 See Willigenburg and Belaere, supra note 8, at 395-96.

340 See Winick, supra note 95 , at 87.

341 See, e.g., UHCDA § 1(3).

342 Sheetz, supra note 9, at 414-15; UHCDA $\S 2$. 
Courts determine legal incompetence, but physicians determine incapacity. ${ }^{343}$ A legal incompetence activation standard does not empower patients to prevent damage caused by mental illness for two reasons. First, a legal incompetence activation standard vests judges with the authority to determine when the directive becomes active even though judges have no specialized training in mental illness or in evaluating a patient's mental state. ${ }^{344}$ Second, the legal incompetence activation standard obstructs the patient's ability to obtain care. If a court determination is required before a directive becomes active, many patients will not be able to obtain intervention in time. Because physicians, not courts, determine capacity, selecting incapacity as the default activation standard when patients fail to designate one better serves patients. ${ }^{345}$

An involuntary commitment activation standard is even more problematic for patients attempting to obtain early intervention than an incompetence standard because a person cannot be committed involuntarily unless he is dangerous or gravely disabled a very high threshold. ${ }^{346}$ This strict standard delays intervention. ${ }^{347}$ Capacity is an appropriate default standard for a Ulysses arrangement because the arrangement's purpose is to obtain early intervention and avoid commitment. For directives which refuse treatment, early activation ensures that doctors follow patient wishes despite the fact that an episode may obstruct the patient's ability to express refusals.

Admittedly the incapacity activation standard has its drawbacks. First, capacity is often fluid and difficult to determine for patients with mental illness. ${ }^{348}$ Second, a physician capacity determination takes time. However, the delays are not nearly as long as those caused by court hearings and rulings.

One of the only strengths of the Uniform Act in the mental health context is its decision to allow patients to determine the triggers that allow their directives to take effect. This decision facilitates early intervention even more than an incapacity activation standard. If the patient does not designate a different circumstance, the power of attorney for health care becomes effective when the primary physician determines the patient has lost capacity. ${ }^{349}$ The Uniform Act commentary uses the following example to illustrate patient designated activation. ${ }^{350}$ A mother may not want to continue to make her own health care

343 Sheetz, supra note 9, at 415; Jessica Wilen Berg et al., Constructing Competence: Formulating Standards of Legal Competence to Make Medical Decisions, 48 RuTGERS L. REV. 345, 345-49 (1996).

344 Washington v. Harper, 494 U.S. 210, 210, 231-32 (1990) (concluding that a person's interests are better served by allowing the decision to medicate to be made by a medical professional rather than an untrained judge); Sabatino, supra note 2, at 1245 (asserting that the Commissioners wanted to keep most health care decisions out of court).

345 See Sheetz, supra note 9, at 401.

346 See supra Part I.B.

347 Id.

348 See supra notes $105-106$ and accompanying text.

349 UHCDA $\S 2$ (c).

$350 \mathrm{Id}$. $2(\mathrm{c}) \mathrm{cmt}$. 
decisions and may prefer that her daughter make them for her. This mother may specify that her daughter should immediately have power of attorney, even before the mother becomes incapacitated. The mother retains the right to revoke the power of attorney at any time if she does so in writing.

Unlike the Uniform Act, the majority of states with separate mental health directive statutes do not allow directives to become active until the patient has lost capacity. ${ }^{351}$ However, like the Uniform Act, some states empower a person to create a mental health directive which takes effect before loss of capacity. ${ }^{352}$

Although the Commissioners adopted the standard that best empowers patients, patient designated activation, the Commissioners should provide more guidance on patient designated activation in the mental health context. Scholars contend activation before loss of capacity is important in the mental health context because early activation enables patients to prevent crisis. ${ }^{353}$

The following is an example of a patient-designated activation clause:

My bipolar disorder follows a pattern. Normally, I take my medication and remain stable. However, stress can make me lose sleep, which causes me to become hypomanic. When I am hypomanic, I no longer recognize my need for treatment and stop my medication. While I'm hypomanic, it is possible that my physician may determine I still technically possess capacity. Left untreated, my condition will deteriorate until I become psychotic.

This directive shall become active when my daughter and brother execute a signed affidavit, listing observed symptoms and attesting that they have concluded that I have become hypomanic. I have decided not to require a court determination of my incompetence or a physician's determination of my incapacity to activate this directive because such a requirement would delay treatment.

This patient recognizes that if he chooses incapacity, as determined by his psychiatrist as the activation standard, all of the following will have to take place before treatment. Someone will have to transport the patient to his psychiatrist. He will resist. Someone will have to make an appointment with his psychiatrist. Even if he obtains an appointment, when the patient is hypomanic, he will not

351 VHA Report, supra note 10 , at 8 (stating that in the 19 states with separate statutes, directives don't become active until the patient loses capacity).

352 ME. Rev. STAT. TIT. 18-A, § 5-802 (2013); N.J. STAT. ANN. § 26:2H-108 (WEST 2013); N.M. Stat. AnN. § 24-7B-4 (2013); 20 PA. Cons. Stat. ANN. $\$ 5824$ (2013); Wash. Rev. CodE ANN. §71.32.060 (2013); see also VHA Report, supra note 10, at 8 (asserting that the states previously listed allow for activation before incapacity).

353 Janet Ritchie et al., Advance Directives in Psychiatry: Resolving Issues of Autonomy and Competence, 21 INT'L. J.L. \& PSYCHIATRY 245 (1998); Gary N. Sales, The Health Care Proxy for Mental Illness: Can It Work and Should We Want It To? 21 Bull. AM. ACAD. PSYCHIATRY \& L. 161 (1993); VHA Report, supra note 10, at 8. 
want treatment. He will try to convince his psychiatrist of his capacity. The psychiatrist may not be accustomed to working with directives ${ }^{354}$ and will be reluctant to hospitalize the patient pursuant to the directive. Instead, the patient has listed two people he trusts and has required them to sign an affidavit attesting to their observations. For him, this strikes the right balance between protection against undue influence and obtaining early intervention. The patient should be free to make this choice.

This activation clause is considered an early activation clause because it activates the directive before a physician has determined he has lost capacity. ${ }^{355}$ Critics argue early activation is problematic because it creates potential for coercion, which in this instance is brought on by the power vested in family members to activate the directive. However, every patient should be free to create an individualized plan. ${ }^{356}$ This freedom results in a lack of standardization of directives. Therefore, the patient, his physician, and the trusted family members will need to be sure of what the plan entails. A patient concerned about family having too much control can rely on the presumptive activation standard of a physician determination of incapacity. ${ }^{357}$ The Uniform Act, which authorizes patient designated activation, clarifies that a patient with capacity may override her directive or the instructions of her agent. This is another protection against coercion. ${ }^{358}$

\section{E. Expiration}

The Commissioners did not provide for automatic expiration of directives. Rather, directives expire under their own terms or when principals revoke them. However, many state mental health directive statutes ${ }^{359}$ provide for automatic directive expiration after a specified time frame, usually somewhere between two and five years. No state legislature imposes this arbitrary expiration ${ }^{360}$ on generic directives.

Advocates of automatic expiration assert the following rationale. First, as technology evolves, treatment options change. ${ }^{361} \mathrm{~A}$ patient's mental illness evolves over the course of the patient's life. Automatic expiration of mental health directives ensures directives continue to reflect patients' treatment instructions over time as their illnesses and treatment options evolve. Second, automatic expiration requires patients to engage in ongoing dialogue with doctors

\footnotetext{
354 See supra note 295 and accompanying text.

355 VHA Report, supra note 10 , at 8.

356 Sheetz, supra note 9 , at 403.

357 UHCDA § 2(c)-(d) \& cmt.

358 VHA Report, supra note 10, at 4.

359 See VHA Report, supra note 10, at 10; see, e.g., OHIo Rev. COde ANN. \$2135.03 (West 2013); Or. Rev. Stat. AnN. § 127.702 (2013); Tenn. CODE ANN. § 33-6-1003 (2013); Tex. Civ. PraC. \& REM. CODE ANN. § 137.002(b) (West 2013).

360 VHA Report, supra note 10 , at 10.

361 Id.
} 
and periodically reassess treatment instructions. ${ }^{362}$ This therapeutic process results in improved decision-making.

Despite these purported benefits, automatic expiration of mental health directives imposes a burden only on patients with mental illness. This burden is unjustified, impractical, and unfair. ${ }^{363}$ First, imposing automatic expiration only on mental health directives unjustifiably treats patients with mental illness differently than other patients. The alleged policy reasons supporting automatic expiration of mental health directives apply equally to generic directives. Technology constantly evolves for end-of-life treatment just as it does for mental health treatment. Patients planning for end-of-life care would also benefit from ongoing dialogue with their physicians. ${ }^{364}$ Just as treatment preferences and goals evolve over time for patients with mental illness, preferences change for the terminally ill.

Second, automatic expiration poses significant administrative burdens only on patients with mental illness who are forced to track the age of directives and re-execute directives every couple of years. ${ }^{365}$ Few patients execute mental health directives. ${ }^{366}$ It is likely that even fewer patients would monitor the age of their mental health directives.

Third, requiring automatic expiration only for mental health directives stigmatizes patients with mental illness and undermines parity for mental health care. ${ }^{367}$ The National Ethics Committee of the Veterans Health Administration indicated that it knew of no evidence supporting the proposition that instructions in a mental health directive "are less stable" than patient instructions in a generic directive. ${ }^{368}$

However, the automatic expiration administrative burden is necessary only for Ulysses arrangements, not revocable mental health directives, for the following reasons. First, automatic expiration helps address concerns about unanticipated consequences due to a patient's change of heart or failure to foresee all contingencies. Automatic expiration after a few years would require the patient to reaffirm her decision to have a Ulysses arrangement. Reaffirmation would help ensure that the patient continues to want physicians to override her illness-induced refusals of treatment.

Second, automatic expiration only of Ulysses arrangements helps address concerns critics raise that consent provided in a Ulysses arrangement is not valid informed consent because it is not contemporaneous. These critics argue that when doctors treat a patient in accordance with her directive, despite

362 Id.

363 Id.

364 See id.

$365 \mathrm{Id}$.

366 See supra note 295 and accompanying text.

367 VHA Report, supra note 10, at 4.

368 Id. 
contemporaneous objections, the doctors rely on expired consent. ${ }^{369}$ Automatic expiration does not guarantee that consent is happening at the moment of treatment, but it does help ensure that the patient has given consent to her directive relatively recently. This is because automatic expiration requires the patient to reaffirm the directive every couple of years. ${ }^{370}$

\section{F. Advance Consent to Intrusive Treatments, the Role of Proxies, and Patients Who Fail to Plan}

This section describes mental health treatments a person might address in a directive. It explores how the Uniform Act addresses advance consent to intrusive treatments, the selection and authority of proxies, and situations when a patient fails to plan. Next, it surveys state approaches to selection of proxies and advance consent to intrusive treatments. Finally, this section evaluates the Uniform Act approach to conclude that it poses undue risks to patients.

\section{Mental Health Treatments}

A basic understanding of mental health treatments is necessary to evaluate whether the Uniform Act provides sufficient guidance on advance consent to such treatments. Doctors did not use psychiatric (also known as psychotropic) drugs to treat mental illness until the late 1940s after the discovery that lithium effectively treated bipolar disorder. ${ }^{371}$ Antipsychotic medications are a class of psychiatric medications doctors began using to treat psychosis in the $1950 \mathrm{ss}^{372}$ In the beginning, antipsychotic medications proved effective in limiting psychosis. $^{373}$ Censuses in state psychiatric hospitals dropped in the years following the widespread use of antipsychotic drugs. ${ }^{374}$ It soon became obvious that while antipsychotic medication minimized psychosis, it also potentially caused serious side effects. ${ }^{375}$ Because of the side effects of various psychiatric medications, courts and legislators consider psychiatric medication to be an intrusive treatment. ${ }^{376}$ In the $1990 \mathrm{~s}$, the United States Food and Drug Administration approved some new antipsychotic drugs for treating patients with

369 See supra notes $187-189$ and accompanying text.

370 See e.g., OH. Rev. Code. Ann. §2135.03 (2013); Tenn. Code Ann. § 33-6-1003(a) (2013); Tex. Civ. Prac. \& Rem. Code ANN. $\$ 137.002$ (b) (West 2013).

371 See SLOBOGIN ET AL., supra note 47, at 23.

372 Douglas Mossman, Unbuckling the "Chemical Straitjacket": The Legal Significance of Recent Advances in the Pharmacological Treatment of Psychosis, 39 SAN DIEGO L. REv. 1033 (2002).

373 Perlin, supra note 54 , at 400 .

$374 \mathrm{Id}$. at 398.

375 Id.

376 Washington v. Harper, 494 U.S. 210, 221-22 (1990). 
psychotic disorders. ${ }^{377}$ Although these medications are not always effective and do not cure the illness, they are possibly more effective than the older antipsychotic medications. ${ }^{378}$ The new drugs are "atypical" because they are different than the older antipsychotic medications in that they alleviate psychotic symptoms with fewer side effects. ${ }^{379}$

Electroconvulsive therapy (ECT), generally considered to be a more invasive treatment than drug therapy, ${ }^{380}$ directs electric currents to parts of the brain, which induces a series of seizures. ${ }^{381}$ There is not yet a scientific consensus on the explanation for the purported therapeutic benefits of ECT. ${ }^{382}$ Historically, patient advocates criticized ECT because of its side effects, such as memory loss, dental trauma, bone fractures, and skin burns. ${ }^{383}$ Today, improved technology for administering ECT combined and improvements in muscle relaxants have resolved many of the side effects. ${ }^{384}$ However, certain side effects remain, including memory loss, which can result in permanent memory gaps. ${ }^{385}$ Although the modern psychiatric community recognizes ECT as an effective and safe treatment for patients who suffer from severe depression and a viable alternative for patients unable to take medication or for whom medication is ineffective, the community is not in unanimous agreement with critics saying that ECT is ineffective and can damage the brain. ${ }^{386}$

The California legislature defines psychosurgery as including operations referred to as lobotomy, psychiatric surgery, behavioral surgery, ${ }^{387}$ or any surgery performed to modify or control thoughts, feelings, or behavior, rather than treat a known, diagnosed physical disease of the brain. ${ }^{388}$ Doctors used prefrontal lobotomy for decades to treat depression, bipolar disorder, obsessive-compulsive disorder, and schizophrenia. ${ }^{389}$ Today, the medical community considers prefrontal lobotomy to be a discredited, dangerous treatment whose benefits are

377 Mossman, supra note 372, at 1039 (The new drugs are clozapine, risperidone, olanzapine, quetiapine, and ziprasidone.).

378 Id.

$379 \mathrm{Id}$, at $1039-40$.

380 See infra note 427 and accompanying text.

381 Mike E. Jorgensen, Is Today the Day We Free Electroconvulsive Therapy?, 12 QUinNiPiaC HEAlTh L.J. 1, 3-4 (2008).

382 Helia Garrido Hull, Electroconvulsive Therapy: Baby Boomers May Be in for the Shock of

Their Lives, 47 U. LouISVILLE L. REv. 241, 251 (2008).

383 Jorgensen, supra note 381 , at 10.

384 SLOBOGIN ET AL., supra note 47, at 27.

385 Hull, supra note 382, at 254-56; In re Estate of Austwick, 656 N.E.2d 779, 781 (Ill. App.

Ct. 1995) (listing fractures, memory loss, confusion, delirium, and in rare instances, death as side effects).

386 Hull, supra note 382 , at $251,259$.

387 See CAl. Code Welf. \& InST. § 5325 (West 2013).

388 Id.

389 Henry T. Greeley, Neuroscience and Criminal Justice: Not Responsibility but Treatment, 56 U. KAN. L. REV. 1103, 1111-12 (2008). 
outweighed by the significant risks of permanent brain damage. ${ }^{390}$ Modern psychosurgery techniques are referred to as stereotactic procedures and involve creating small lesions in different areas of the brain. ${ }^{391}$ Generally, even these modern procedures are rarely used and considered highly intrusive. ${ }^{392}$ When performed, the procedures are typically restricted to hospitalized patients with very serious mental disorders only after less intrusive therapies have failed. ${ }^{393}$

\section{The Uniform Act Approach}

Health care decisions of the guardian, agent, or surrogate are effective without judicial approval. ${ }^{394}$ If neither the patient nor the court has designated a proxy, or the proxy is unavailable, any available family member may act as surrogate under a priority system starting with the spouse. ${ }^{395}$ The surrogate must promptly inform the other family members of her assumption of authority. ${ }^{396}$ Unless the person is related to the patient, an owner, operator, or employee of a residential long-term health care institution at which the patient receives care may not act as a surrogate or agent. ${ }^{397}$ The patient may disqualify a person from acting as her surrogate by a signed writing or by informing her doctor. ${ }^{398}$ The Uniform Act imposes no other safeguards against the nomination of proxies who might depart from patient wishes. ${ }^{399}$

If members of a class of surrogates who have equal priority (i.e. siblings) disagree about a treatment decision, majority rule applies. ${ }^{400}$ If these surrogates are still evenly divided, the decision-making process stops ${ }^{401}$ and a courtappointed guardian makes the decision. ${ }^{402}$ Agents and surrogates must make decisions in accordance with the patient's instructions or known wishes. ${ }^{403}$ If there are no instructions, agents and surrogates shall make decisions pursuant to the patient's best interests while considering the patient's values. ${ }^{404}$

A patient can consent to mental health treatment in a directive by issuing instructions and/or designating a proxy, thereby avoiding the time consuming

390 Id.

391 Id.

392 SLOBOGIN ET AL., supra note 47, at 32.

393 Id: 1 KAPLAN \& SADOCK's COMPREHENSIVE TeXtBooK OF PSychiatry 1914 (Benjamin J. Sadock et al., eds., 9th ed. 2009).

394 UHCDA $\S \S 2(\mathrm{f}), 5(\mathrm{~g}), 6(\mathrm{c})$; see also id. $\S 6(\mathrm{~b})$.

395 Id. $\S 5(\mathrm{~b})$.

396 Id. \& 5(d).

397 Id. $\$ 5(\mathrm{i})$.

398 Id. § 5(h).

399 See Stith, supra note 2, at 58.

400 UHCDA $\S 5(\mathrm{e}) \& \mathrm{cmt}$.

401 Id.

402 Id. $\S 5$ (e) \& cmt., 14; see Sabatino, supra note 2, at 1249.

403 UHCDA $\S \S 2(\mathrm{e}), 5(\mathrm{f})$.

404 Id. 
process of resorting to a court-appointed proxy. ${ }^{405}$ Whether a patient can grant a surrogate or agent the authority to consent to inpatient mental health treatment has been the subject of debate and was the impetus for the 1999 amendment to the Uniform Act. ${ }^{406}$ As amended, the Uniform Act now prohibits agents and surrogates from consenting to the patient's inpatient mental health treatment unless the written directive expressly provides such authority. ${ }^{407}$

Despite the requirement for express written authorization for an agent or surrogate to consent to inpatient mental health treatment, the Uniform Act does not seem to require express written authorization for an agent or surrogate to consent to outpatient ECT or psychotropic medication. ${ }^{408}$ This is because the Uniform Act's broad grant of authority to agents and surrogates includes the authority to make all health care decisions for the patient. ${ }^{409}$ Health care decisions include selection and discharge of doctors, approval and disapproval of tests, surgeries, medications, and orders to resuscitate, and directions to provide, withhold, or withdraw artificial nutrition, hydration, and other care. ${ }^{410}$ This definition appears broad enough to encompass ECT, psychotropic medication, and even psychosurgery. However, the Uniform Act and its commentary do not explicitly mention ECT, psychotropic medication, or psychosurgery. Rather, the enumerated examples of health care decisions focus on end-of-life decisions.

Under the Uniform Act, clinicians and institutions have the duty to comply with a patient's instructions as well as a proxy's decisions. ${ }^{41 !}$ Decisions of agents, surrogates, and guardians obligate the clinician or institution to the same extent as the patient's instructions. ${ }^{412}$ Override provisions delineate limited instances in which the physician need not follow the directive. ${ }^{413}$ First, clinicians and institutions may refuse to implement instructions or a proxy's decisions for reasons of conscience. ${ }^{414}$ Second, clinicians and institutions may refuse to implement instructions or a proxy's decisions requiring medically ineffective care or treatment contrary to accepted standards. ${ }^{415}$ When the clinician or institution refuses to treat in accordance with the instruction or proxy decision,

405 Id. $\S 2$.

406 Cohen v. Bolduc, 760 N.E.2d 714, 613, 614 nn.13 \& 14 (Mass. 2002); see also Winick, supra note 95 , at $81-86$.

407 UHCDA § 13(e) (clarifying that UHCDA does not address whether a guardian has authority to consent to the principal's inpatient mental health treatment but leaving that matter to state guardianship law); see also id. $\S 13(\mathrm{f})$ (stating that UHCDA does not affect mental health treatment of involuntarily committed people because state law addresses this matter).

408 Id. $\S \S 1(2), 1(6) .1(17), 2,5$.

409 Id. $\S 1(6), 2(\mathrm{~b}), 5(\mathrm{a})$.

410 Id. $\$ 1(6)$.

411 Id. $\S 7(\mathrm{~d})$.

412 Id.

413 Id. $\S 7(\mathrm{e})-(\mathrm{f}) ;$ see VHA Report, supra note 10, at 6.

414 UHCDA \& $7(\mathrm{e})$.

415 Id. § 7(f). 
they must notify the patient or her authorized representative. ${ }^{416}$ Moreover, they must make reasonable efforts to assist in transferring the patient to another facility willing to comply with the directive and provide continuing care until transfer. $^{417}$

\section{State Approaches}

Most states provide broader protection against health care fraud than the Uniform Act does, by removing people affiliated with any facility treating the patient. ${ }^{418}$ Some states that have implemented the Uniform Act have amended the Uniform Act's automatic surrogate selection priority system to safeguard against selecting a surrogate who might depart from patient values. ${ }^{419}$ For example, Delaware disqualifies a spouse when there has been a complaint of domestic abuse. ${ }^{420}$ Hawaii refused to enact the priority list and selects surrogates based on consensus of interested parties. ${ }^{421}$

Whether a principal can convey authority to an agent to consent to the principal's admission in a mental health facility depends on the principal's state of residence. Some states authorize patients to create mental health directives but do not allow patients to empower an agent to consent to inpatient mental health treatment. $^{422}$ In North Dakota, patients are allowed to convey an agent authority to consent to voluntary commitment of the patient for up to 45 days but are not allowed to consent to a commitment for any greater length of time. ${ }^{423}$ Other states follow the Uniform Act approach by allowing an agent to consent to the principal's inpatient treatment only with express authority in a written directive. ${ }^{424}$ Finally, some states allow an agent to consent to the principal's inpatient mental health treatment even without express commitment authority as long as the grant of authority is sufficiently broad. ${ }^{425}$

Whether a patient may use a directive to consent to intrusive treatments also depends on the principal's state of residence. Many states prohibit patients from consenting to or conveying authority to an agent to consent to psychosurgery in a

416 Id. $\S 7$.

417 Id.

418 See, e.g., Alaska Stat. § 13.52.010(c) (2013); Cal. Prob. Code $\S 4659$ (a)-(b) (2013).

419 Stith, supra note 2 , at 58 .

420 DEL. CODE ANN. TIT. 16, § 2507(b)(2)(f) (2013).

421 Stith, supra note 2, at 58.

422 See, e.g., Tex. Health \& Safety Code AnN. § 166.152(f)(1) (West 2013); Wis. Stat. ANN. $\S 155.20(2)$ (West Supp. 2013); Cohen v. Bolduc, 760 N.E.2d 714, 714, 718 n.15 (Mass. 2002).

423 N.D. CENT. CODE § 23-06-5-03 (2013); Cohen, 760 N.E.2d at 718 n.15.

424 See, e.g., ARIZ. Rev. Stat. \$36-3283(f) (West Supp. 2013); Fla. Stat. AnN. $\S 765.113(1)$ (West 2013); HaW. Rev. STAT. § 327E-13(e) (2013); Miss. CODE ANN. § 41-41227(5) (Lexis Nexis 2013); Cohen, 760 N.E.2d at 719 n.17.

425 See, e.g., Cohen, 760 N.E.2d at 723. 
directive. ${ }^{426}$ Several states do not empower a principal to convey authority, even expressly, to an agent to consent to the principal's ECT; a court order is required. ${ }^{427}$ Kentucky empowers patients to issue binding refusals of treatments but, arguably, does not empower patients to issue binding consents. ${ }^{428}$ This is because Kentucky explicitly authorizes patients to use directives to refuse specific medications or ECT but only to state preferences for medications or emergency interventions. ${ }^{429}$ This language suggests doctors are bound to adhere to the patient's refusals and must consider patient medication preferences but are not required to administer those medications. ${ }^{430}$ Finally, some states empower a principal to use a directive to consent to and convey authority to an agent to consent to intrusive treatments, including $\mathrm{ECT}^{431}$ and psychotropic medication. ${ }^{432}$

\section{Analysis}

\section{Insufficient Protection under the Uniform Act's Proxy Limitations}

The Uniform Act limitation of the potential agent and surrogate pool does not protect patients with mental illness, particularly against health care fraud. There is evidence that health care fraud is more pervasive in the mental health sector. ${ }^{433}$ Therefore, patients with mental illness are more vulnerable than other patients to receiving treatment they do not need or to which they have not consented. A person who has a financial incentive in administering treatment

426 See, e.g., Cal. Prob. Code $\S 4652$ (West 2013); Or. Rev. Stat. $\$ 127.540$ (2013); Tex. Health \& Safety Code ANN. $\$ 166.152$ (West 2013); Wash. Rev. Stat. $\$ 11.92 .043$ (2013) (prohibiting a guardian from consenting to surgery solely for the purpose of psychosurgery).

427 See Jorgensen, supra note 381 , at 1 (stating that many states require proxies to obtain prior court authorization before consenting to ECT on behalf of an incapacitated ward); see, e.g., CAL. Prob. CODE $\S 4652$ (West 2013); DC STAT. § 7-1231.07(e) (2013); N.H. Rev. STAT. § 464-A:25 (2013); OR. REv. STAT. § 127.540 (2013); TeX. Health \& SAFETy COdE ANN. § 166.152(f) (2013).

428 See KY. REv. STAT. § 202A.422 (West 2013); Sheetz, supra note 9, at 425.

$429 \mathrm{KY}$. REv. STAT. § 202A.422 (West 2013).

$430 \mathrm{Id}$.

431 ECT is more regulated than psychotropic medication. See Jorgensen, supra note 381 , at app. A (providing a table of state statutes concerning ECT); see, e.g., MICH. COMP. LAW $\$ 330.1717$ (2013) (prohibiting administration of ECT without consent from the patient, the guardian, or the agent if the directive grants the agent authority to consent to ECT); WASH. REv. STAT. $\S \S 71.32 .260,71.32 .160$ (2013) (allowing the principal to indicate whether she consents and authorizes her agent to consent to administration of ECT).

432 See, e.g., IND. CODE $\S 16-36-1.7-3$ (2013) (authorizing a patient to specify in a directive psychotropic medication, electroconvulsive therapy, and inpatient treatment); MINN. STAT. $\S 253 \mathrm{~B} .03(6)(\mathrm{d})(2013)$; N.C. GEN. STAT. ANN. $\$ 122 \mathrm{C}-73$ (West 2013) (allowing use of a directive to grant or withhold authority for psychotropic medication, electroconvulsive therapy, and inpatient mental health treatment); WASH. REV. STAT. $\$ \S 71.32 .100,71.32 .050,71.32 .260$ (2013) (authorizing a patient to make a declaration consenting to or refusing intrusive mental health treatments and to convey authority to a proxy to make decisions about intrusive mental health treatments).

433 See supra note 326 and accompanying text. 
should not serve as the patient's agent, unless she is a family member. The Commissioners recognized that patients in nursing homes are particularly vulnerable and therefore prohibited people affiliated with the patient's nursing home from being the patient's surrogate or agent. ${ }^{434}$ However, this should not be the only limitation on the potential surrogate pool because most patients receive mental health care outside of long-term residential health care institutions. Unless the person is related to the principal, no owner, operator, employee, or agent of any facility where the principal receives care should act as an agent or surrogate.

\section{Too Much Authority to Automatically Selected Surrogates}

Although the Uniform Act's definition of health care decisions appears broad enough to encompass ECT, psychotropic medication, or even psychosurgery, the Uniform Act and its commentary never specifically address any of these intrusive treatments. ${ }^{435}$ This vacuum of guidance combined with the Uniform Act's broad grant of authority to surrogates the principal never chose ${ }^{436}$ poses undue risks of coercion and undue influence.

The following story illustrates how the Uniform Act's lack of guidance on mental health treatments combined with broad authority to automatically selected surrogates poses undue risks. In the past, Ms. Jones alleged that Mr. Jones abused her. She voluntarily admits herself in the psychiatric ward because she is severely depressed. After admission her psychiatrist determines that she has lost capacity. She has no guardian, agent, or directive. In the past, Ms. Jones has taken medication to treat her mental illness. She has never expressed any opinion about ECT. Mr. Jones notifies her psychiatrist that he will serve as her surrogate. The psychiatrist explains treatment options to Mr. Jones which include outpatient ECT. Mr. Jones selects ECT to treat his wife. Her siblings and parents disagree. Although they have never discussed ECT with Ms. Jones, they believe she would not want to receive it. They also do not trust Mr. Jones. Nonetheless, Mr. Jones authorizes ECT.

Unless administering ECT violates the doctor's conscience, is an ineffective treatment, or contrary to accepted standards (triggering the Uniform Act override provision), the doctor must comply with the patient's decision and administer ECT. ${ }^{437}$ Most likely, none of these narrow exemptions apply to ECT, which, despite its side effects, is recognized as an effective treatment. Even if the doctor refuses to administer ECT under the override provision, the doctor must make reasonable efforts to transfer Ms. Jones to a facility willing to administer ECT. ${ }^{438}$ The Uniform Act requirement for Ms. Jones's express written authorization to

434 Sabatino, supra note 2, at 1243-44.

435 UHCDA § 1(6).

436 Id. $\S 5(\mathrm{a})$.

437 Id. $\S 7(\mathrm{~d})-(\mathrm{f})$.

438 Id. $\S 7(\mathrm{~g})$. 
enable a proxy to consent to her inpatient mental health treatment does not limit Mr. Jones's power to consent to his wife's outpatient ECT. ${ }^{439}$

Although Mr. Jones must have express authority to consent to his wife's inpatient mental health treatment, the Commissioners failed to impose such a requirement on outpatient psychotropic medication, ECT, or psychosurgery. ${ }^{440}$ Because Ms. Jones left no instructions, Mr. Jones is supposed to make her health care decisions based on his estimation of what is in her best interests. ${ }^{441}$ Based on their history, it is quite possible that he would not make decisions in her best interests. Invoking one of the few Uniform Act safeguards, one of Ms. Jones's family members may petition the court for an injunction to stop administration of ECT. ${ }^{442}$ However, if no family member cares enough to do so or if the family member does not prevail, Mr. Jones's decision controls the course of treatment. The history of domestic violence does not limit his power to make health care decisions for Ms. Jones because the Commissioners neglected to remove from the surrogate pool family members who might depart from patient values. ${ }^{443}$ Neither Ms. Jones nor a court evaluated whether Mr. Jones could be trusted to make decisions in line with his wife's values. Most likely, Ms. Jones would not have chosen Mr. Jones.

It is appropriate for the Uniform Act to create a decision-making framework for the vast majority of the population who fails to plan for end-of-life care. ${ }^{444}$ Turning to family makes sense. ${ }^{445}$ However, one size does not fit all. In the mental health context, arbitrarily selecting the spouse to be surrogate because he is first in line undermines patient autonomy. The Uniform Act's grant of unchecked authority to a single family member whom the patient never chose ignores the realities of mental illness which often devastates familial relationships, especially marriages. ${ }^{446}$ Even in the absence of domestic abuse, many patients would not want their spouses, acting alone without court approval, to have the power to authorize ECT, psychotropic medication, or psychosurgery. The Uniform Act's failure to remove from the surrogate pool individuals who might depart from patient values undermines patient autonomy and risks coercion and undue influence.

\section{Look To Patient's Grant of Authority}

When a surrogate is automatically selected, the patient has no input.

439 Id. $\S 13(\mathrm{e}) \& \mathrm{cmt}$.

$440 I d . \S 13(\mathrm{e})$.

441 Id. $\$ 5(\mathrm{f})$.

442 Id. $\S 14$.

443 Stith, supra note 2 , at $57-58$.

444 See Sabatino, supra note 2, at 1248-49.

445 FURROw, supra note 100 , at 849.

446 Davoli, supra note 10, at 1045 (recommending early intervention before a mental illness erodes a patient's support system). 
Providing broad authority to an agent the patient selected is less problematic. The patient maintains influence over her care. ${ }^{447}$ When the patient has capacity, she can communicate her preferences to her agent. She can select an agent she trusts to make decisions consistent with her values. However, the Uniform Act does not authorize an agent to consent to the principal's inpatient mental health treatment based on the principal's grant of unlimited health care decision-making authority to the agent. ${ }^{448}$ The Act prohibits an agent from consenting to the principal's admission to a mental health care institution unless the principal's written directive expressly provides such authority. ${ }^{499}$ Cohen v. Bolduc underscores the reasons why this arbitrary limitation undermines patient autonomy. ${ }^{450}$

In Cohen v. Bolduc, the Massachusetts Supreme Court analyzed whether Massachusetts' general health care proxy statute authorized an agent to commit a principal to a mental health facility when the principal did not oppose. ${ }^{451}$ The principal's health care proxy stated:

My Health Care Agent is granted full power and authority to consent to any and all medical treatment which I may need in the event that I am unable to consent ... including without limitation authority to consent to medical care, hospitalization, nursing home admission, or whatever else may in my Health Care Agent's sole judgment be in my best interest . . . . I further state ... that there are no limitations imposed upon my Health Care Agent's authority. ${ }^{452}$

The proxy was activated when Bolduc's psychiatrist decided Bolduc lacked capacity. ${ }^{453}$ Bolduc's psychiatrist admitted Bolduc into a mental health facility under Massachusetts's emergency psychiatric hospitalization procedures. Bolduc's agent then converted Bolduc's admission status to conditional voluntary, a status which imposed no temporal limits on Bolduc's hospitalization. Had her agent not done so, Massachusetts law would have required the hospital to file a petition to retain Bolduc involuntarily which would have required proof that Bolduc met strict involuntary commitment criteria. Later, Bolduc revoked her proxy and demanded discharge from the hospital. ${ }^{454}$

The Massachusetts statute did not address whether the principal's grant of unlimited decision-making authority conveyed to the agent the authority to consent to the principal's inpatient mental health treatment. ${ }^{455}$ However, the

447 See Winick, supra note 95 , at 82-85.

$448 \mathrm{UHCDA} \S 13(\mathrm{e})$.

449 Id.

450 Cohen v. Bolduc, 760 N.E.2d 714, 720-24 (Mass. 2002).

$451 \mathrm{Id}$. at 715 .

452 Id.

$453 \mathrm{Id}$. at 716.

$454 \mathrm{Id}$. at $716-17$.

$455 \mathrm{Id}$. at 718 . 
proxy statute granted an agent the authority to make any health care decisions for the principal and defined "health care" broadly to include treatment of "mental conditions." had the authority to commit the principal to a mental health facility. ${ }^{457}$

Cohen also considered the policy implications and wisely determined that prohibiting an agent from committing her principal frustrated the purpose of the proxy statute to support patient autonomy. ${ }^{458}$ Under the statute, the agent's decisions had the same effect as the principal's decisions. Cohen correctly stated that restricting the range of advance planning choices unduly limited the principal's ability to control her own care. The Cohen court departed from the Uniform Act by not requiring express authority in a written directive to empower the agent to commit the principal. ${ }^{459}$ The principal's grant of unlimited authority to make health care decisions was deemed sufficient.

For a directive to be an effective tool, a patient must be able to use the directive to consent to mental health treatments and empower an agent to do the same. The Uniform Act's requirement for express authority in a written directive for an agent to consent to inpatient mental health treatment ${ }^{460}$ undermines patient autonomy for the following reasons.

First, arbitrary limitations on an agent's ability to consent to the principal's treatment will result in principals not receiving care they need and to which they consented. The Uniform Act requires the principal to appreciate that she must use "magic" words conveying authority to an agent to consent to her admission in a mental health institution. ${ }^{461}$ It is illogical that Bolduc's written grant of unlimited authority to make health care decisions to her daughter would not include the right to consent to admission in a mental health facility. ${ }^{462}$ However, had the Massachusetts Supreme Court applied the Uniform Act, this would have been the illogical result. ${ }^{463}$ Patients who grant unlimited authority to agents have the right to expect that doctors and agents will look to the patient's own words to determine the scope of the agent's authority.

Second, limiting a patient's right to consent, in advance, to inpatient and pharmacological mental health treatment imposes a unique burden on patients with mental illness who have been historically stigmatized. States provide patients the authority to refuse life-sustaining treatment, either through instructions or through agents. ${ }^{464}$ The U.S. Supreme Court has recognized that the right of patient autonomy can outweigh the significant state interest in

456 Id. at 720

457 Id.

$458 I d$. at 721 .

459 Id. at 715 .

460 UHCDA § $13(\mathrm{e}) \& \mathrm{cmt}$.

461 ld.

462 Cohen, 760 N.E. $2 d$ at 715.

463 UHCDA § $13(\mathrm{e}) \& \mathrm{cmt}$.

464 See FURRow, supra note 100, at 829-31. 
preservation of life ${ }^{465}$ No state interest in preserving life is implicated when a patient grants an agent authority to consent to psychotropic medication and inpatient mental health treatment. On the other hand, there is a tremendous patient interest in securing treatment to prevent a crisis.

However, ECT is a unique, invasive treatment. ${ }^{466}$ The Uniform Act fails to mention ECT and can be construed to authorize a surrogate the patient never selected to consent to the patient's outpatient ECT. ${ }^{467}$ Moreover, under the Uniform Act, a patient who conveys broad decision-making authority but never mentions ECT arguably conveys authority to an agent to authorize the patient's ECT. ${ }^{468}$ ECT is more invasive and controversial than pharmacological therapy. ${ }^{469}$ It is for this reason that many states prohibit an agent from consenting to ECT without a court order. ${ }^{470}$ Because ECT is an effective treatment for many patients, patients should be able to consent to and convey authority to an agent to consent to the patient's ECT. ${ }^{471}$ Considering the invasive nature of ECT, advance consent to ECT should have to be expressed.

\section{No Proxy Consent to Psychosurgery}

The Uniform Act grants the authority to make all health care decisions for the principal when the principal lacks capacity to patients' agents, surrogates, and guardians. ${ }^{472}$ This authority is unchecked because no court approval is necessary. ${ }^{473}$ The Uniform Act's enumerated examples of health care decisions focus on end-of-life decisions and do not mention psychosurgery. ${ }^{474}$ On its face, the broad definition of health care decision appears to include psychosurgery. ${ }^{45}$ Granting a proxy this authority is unwise, which may be why many states prohibit a proxy from consenting to the principal's psychosurgery. ${ }^{476}$ Instead, doctors should use other, less intrusive treatments to restore the patient's capacity. At this point, when the patient has regained full capacity, the patient can decide whether to consent to more invasive treatments such as psychosurgery.

465 See supra notes $151-153$ and accompanying text.

466 See supra notes 380-386 and accompanying text.

467 UHCDA $\S 1(6)$.

468 Id. $\S \S 1(6), 2(\mathrm{~b})$.

469 See supra notes $380-386$ and accompanying text.

470 See supra note 427 and accompanying text.

471 See supra notes 384 and 386.

472 UHCDA $\S 1(6)$.

$473 I d . \S 2(\mathrm{f}), 5(\mathrm{~g}), 6(\mathrm{c})$.

$474 \mathrm{Id}$. $\$ 1(6)$ (iii) (listing orders concerning artificial nutrition and hydration).

$475 \mathrm{Id}$. $\S 1$ (6)(ii) (including approval and disapproval of surgical procedures).

476 See supra note 426 and accompanying text. 


\section{G. Directive Templates}

The Uniform Act provides a model statutory form which allows principals to designate agents and provide instructions. ${ }^{477}$ Principals may check boxes to indicate whether they want to prolong life as long as possible. One section of the form allows the principal to indicate whether she wants artificial nutrition and hydration withheld and whether she wants to donate her organs.

The Uniform Act template fails to address common mental health issues, but more importantly, showing this form at the wrong time to already vulnerable patients could be confusing and unsettling to the patient. One commentator noted that some hospitals are reluctant to provide patients with templates that ask for instructions about harvesting organs because it gives the wrong impression at the wrong time. ${ }^{478}$ This is especially true for the patient who has recently recovered from a mental illness episode and wants to plan for a future episode. Having to address end-of-life issues distracts the patient from the mental illness issues he faces and could deter him from creating a directive.

There are real benefits to offering a template. First, the process of developing a template involves consulting with experts. Stakeholders have an opportunity to resolve potential issues. This process makes it easier for courts to uphold the directive when problems arise. Moreover, providing a preapproved form arguably encourages patients to execute directives. It is simpler for a person to check boxes than it is for the person to craft an individualized health care plan.

However, some scholars argue that the drawbacks of a model form outweigh the benefits. ${ }^{479}$ One scholar observed that "statutory forms tend to become fixed realities with a life of their own that is resistant to change."480 Patients with bipolar disorder, depression, schizophrenia, drug addiction, or various other mental illnesses ${ }^{481}$ may elect to create mental health directives. Even patients diagnosed with one mental illness, such as bipolar disorder, will present in different ways and experience different levels of severity of the illness. ${ }^{482} \mathrm{~A}$ single template cannot address the unique needs of the varied patient population. Psychiatrists should encourage patients to create their own directives tailored to their individual needs. There is a danger that a statutory form will become the standard from which patients are afraid to deviate. ${ }^{483}$

477 UHCDA $\S 4$.

478 Sabatino, supra note 2, at 1248.

479 See supra notes $480-483$.

480 Sabatino, supra note 2, at 1248 .

481 DSM-V, supra note 166, at 87-122 (schizophrenia), 123-88 (mood disorders), 481-590 (substance-related disorders).

$482 \mathrm{Id}$. at $123-54$.

483 See Sabatino, supra note 2, at 1248. 


\section{SOLUTION: ISSUE A MODEL STATUTE}

This Part recommends the Uniform Law Commissioners adopt a model mental health directive statute, because the Uniform Act, with its focus on endof-life, fails people with mental illness. The Uniform Law Commission is the appropriate organization to issue a model statute because its mission is to promote uniform state laws in areas where uniformity is desirable and practical. In the area of advance planning for mental health treatment, patients benefit from uniformity.

In half of the states that have not enacted mental health directive statutes, patients must rely on generic directive statutes that fail to address important mental health issues. Even in the states with specialized statutes, provisions vary widely and often do not meet the needs of patients with mental illness. ${ }^{484} \mathrm{~A}$ person's ability to control her illness should not depend on the state in which she resides. Moreover, patients frequently receive care for acute episodes away from their hometowns. Uniform direction from the Commissioners helps ensure that a patient's directive is valid wherever she receives care.

The model provisions in Appendix A improve on the Uniform Act and the Washington statute. The model provisions fall into the following categories:

(A) Provisions making mental health directives, particularly Ulysses arrangements, effective intervention tools;

(B) Provisions ensuring mental health directives, particularly Ulysses arrangements, are created free from undue influence, coercion, or fraud;

(C) Safeguards ensuring mental health directives, particularly Ulysses arrangements, are properly implemented and not abused; and

(D) Provisions removing obstacles to advance planning.

\section{A. Provisions Making Directives Effective Intervention Tools}

Several of the model provisions are designed to empower patients to use their directives to control their illnesses. The model activation provision provides guidance the Uniform Act fails to give on how patient designated activation works in the mental health context. Many state mental health directive statutes do not allow patients to determine the standard by which their directives become active. Postponing activation until the point at which a physician determines the patient has lost capacity delays care. The model language allows patients to designate when their directives become active and facilitates early intervention.

The Uniform Act imposes the arbitrary requirement for express authority in a written directive for an agent to authorize the principal's inpatient mental health treatment. This burden could deprive people of care they need and to which they consented. Under the model provisions, the plain language of the principal's written grant of authority determines the scope of the agent's authority to consent 
to the principal's inpatient mental health treatment and psychotropic medication. This meets the expectations of a principal who grants unlimited authority to an agent to make her health care decisions.

The Uniform Act fails to address ECT. Some states prohibit an agent from consenting to the principal's ECT. Because ECT is recognized as an effective treatment, the model provisions empower patients to use directives to consent to ECT and to grant authority to agents to do the same.

The model language enables a patient to form a Ulysses arrangement. First, the model legislative findings recognize that issues implicated in end-of-life care differ from issues confronting patients with mental illness and recognizes the value of Ulysses arrangements. The Uniform Act and even the Washington statute prevent people from forming truly self-binding arrangements for care. ${ }^{485}$ The model provision empowers patients to receive three weeks of inpatient mental health care pursuant to their irrevocable directives despite illness-induced refusals.

The model language better enables patients to control their illnesses than the Washington statute does in two ways. First, the model language eliminates the Washington statutory requirement for discharge of an incapacitated patient who demands discharge, even if discharge contravenes her irrevocable directive. ${ }^{486}$ Second, unlike the Washington statute, ${ }^{487}$ the model language creates a rebuttable presumption of incapacity when a patient's irrevocable directive consents to treatment that the patient then refuses under the influence of an episode. This rebuttable presumption recognizes that episodes often cause patients to refuse treatment. Concerned about liability for unlawfully involuntarily treating a patient, doctors will likely adjudge patients as having capacity when episodes cause patients to refuse treatment requested in their directives. ${ }^{488}$ This caution harms the patient because it prevents intervention. The rebuttable presumption encourages doctors to follow the directive, despite the patient's illness-induced objections.

\section{B. Provisions Ensuring Directives are Created Free from Undue Influence, Coercion, or Fraud}

\section{Provisions Applicable to all Mental Health Directives}

The Uniform Act's elimination of the requirement for a signed, witnessed writing $^{489}$ removes protections for patients who are vulnerable to undue influence, coercion, and fraud. The model execution provision contains

485 WASH. ReV. CodE $\S 71.32 .140(6)$ (b) (2013).

486 Id.

487 See supra Section II.B.

488 Id.

489 UHCDA $\S \S 2(a), 5(a)$. 
safeguards the Uniform Act eliminates such as the requirement of a signed writing witnessed by two disinterested people who attest that the principal presented identification and did not appear coerced.

\section{Provisions Applicable Only to Ulysses Arrangements}

Recognizing the sensitivities of administering treatment despite illnessinduced refusals, the model provisions create safeguards to ensure Ulysses arrangements are formed voluntarily by patients with capacity. First, the model provisions give every patient the right to choose whether their directives will be revocable when they lack capacity. No patient should have as her only advance planning option an irrevocable directive. Unlike most state mental health directive statutes, which require capacity to revoke, ${ }^{490}$ the model language allows patients to revoke their directives even when they lack capacity unless they designate otherwise.

Patients who enter Ulysses arrangements must obtain a clinician attestation of patient capacity. Moreover, Ulysses arrangements automatically expire two years after formation unless the patient reaffirms. Automatic expiration helps address concerns about the risks of unintended consequences due to a patient's change of heart or failure to foresee all contingencies. Physicians and patients must engage in ongoing dialogue to ensure the directive remains consistent with the patient's wishes. Automatic expiration also addresses concerns that consent provided in a Ulysses arrangement is not contemporaneous informed consent. Admittedly consent provided through the arrangement is not truly contemporaneous, but automatic expiration ensures that consent is relatively recent.

\section{Safeguards Ensuring Directives are Properly Implemented and Not Abused}

\section{Safeguards Applicable to all Mental Health Directives}

Unlike the Uniform Act, which only excludes from the agent/surrogate pool people affiliated with long-term residential facilities, ${ }^{491}$ the model language focuses on mental health. Many people receive mental health treatment outside nursing homes. To protect against fraud, which is more common in the mental health sector, ${ }^{492}$ the model language removes from the potential agent pool people affiliated with any facility treating the patient.

The model activation provision protects against coercion by clarifying that a directive does not prevail over contemporaneous preferences of a principal with capacity. The model language also prohibits a directive from authorizing

490 See VHA Report, supra note 10 , at 9.

491 UHCDA $\S \S 2(\mathrm{~b}), 5(\mathrm{i})$.

492 See Bucy, supra note 326. 
psychosurgery, a controversial and rarely used treatment. ${ }^{493}$ The Uniform Act's lack of guidance on intrusive mental health treatments combined with broad authority granted to surrogates the principal never selected ${ }^{494}$ poses undue risks of coercion. In the model statute, the Commissioners should eliminate provisions for automatic surrogate selection. People whom neither the principal nor a court selected should not have the power to authorize intrusive mental health treatments.

Because ECT is more controversial and invasive than pharmacological therapy, the model language protects patients by forbidding an agent from consenting to the principal's ECT unless the principal's directive expressly grants such authority.

\section{Safeguards Applicable to Ulysses Arrangements}

The model language sets forth safeguards that address concerns that Ulysses arrangements violate due process because they enable clinicians to forcibly hospitalize and treat a patient even when the patient does not meet commitment criteria. First, doctors must heed treatment refusals from patients with capacity. Second, the model language requires express consent before administering psychotropic medication in contravention of illness-induced objections. Moreover, only licensed psychiatrists may administer the medication and only if two psychiatrists recommend in writing the specific medication. Third, the provisions limit self-binding hospitalization to three weeks. Fourth, although patients may consent in a revocable directive to ECT and authorize an agent to do so, the provisions do not allow Ulysses arrangements for ECT. This is because administering ECT, an invasive treatment, in contravention of contemporaneous objections, creates undue opportunities for coercion. Instead, the patient can use the Ulysses arrangement to obtain intervention, through other means, such as drug therapy. Then, when the patient regains capacity, she can consent to ECT if she so chooses. Fifth, the model language allows patients to seek injunctive relief. All of these safeguards help address concerns that Ulysses arrangements create opportunities for undue influence, abuse, and coercion from doctors and family desperate to conquer the patient's illness.

\section{Provisions Removing Obstacles to Advance Planning}

Some states create obstacles to directive formation that further stigmatize mental illness, such as requiring a capacity determination to create any mental health directive. ${ }^{495}$ The model language creates no unnecessary obstacles to

493 See supra Section II.F.

494 UHCDA § 5(a).

495 See supra note 334 and accompanying text. 
directive formation. Patients need only obtain a capacity determination if they form a Ulysses arrangement.

The Uniform Act contains a template that addresses end-of-life issues and could be confusing and upsetting to otherwise healthy patients with mental illness. This inappropriate template could deter patients from forming a mental health directive. Instead of a template ${ }^{496}$ the Commissioners should provide a range of samples of directives tailored to the needs of patients with different mental health planning needs. Samples would assist the patient create a directive tailored to her own needs. Multiple samples would avoid creating the impression that deviation from a mandatory form could render the directive unenforceable.

\section{CONCLUSION}

Ulysses arrangements enable people to obtain intervention when an acute mental illness episode prevents them from recognizing they need treatment. The Uniform Act purports to be a comprehensive model advance directive statute, which addresses all types of advance health care planning, ${ }^{497}$ but it fails to meet the needs of people with mental illness, most notably by failing to empower patients to form Ulysses arrangements. Washington's approach is touted as being at the forefront of patient empowerment. ${ }^{498}$ However, even Washington prohibits Ulysses arrangements by requiring discharge of an incapacitated patient who demands discharge even when releasing the patient contravenes her irrevocable directive. ${ }^{499}$

The Uniform Law Commissioners should issue a model statute that empowers patients to enter Ulysses arrangements, removes roadblocks to directive formation, creates parity for mental health care, and prevents fraud, coercion, and undue influence. The recommended provisions accomplish these goals. Unlike Washington, the model language does not require doctors to heed a patient's illness-induced discharge demands, which are in contravention of her directive. ${ }^{500}$ Further, the model language creates a rebuttable presumption of incapacity in the event that a patient's irrevocable directive consents to treatment that the patient then refuses under the influence of an episode. ${ }^{501}$ This presumption facilitates treatment because it recognizes doctors will be reluctant to treat a patient in the face of illness-induced refusals. If the Commissioners adopt this model statute and states follow suit, people with mental illness will have more power to control their own treatment.

496 UHCDA $\S 4$.

497 See UHCDA $\S 3$.

498 See WASH. REV. CODE $\$ 71.32 .140$ (2013); Sheetz, supra note 9, at 401, 433.

499 WASH. REV. CODE $\S 71.32 .140(6)(b)$ (2013).

$500 \mathrm{Id} . \S 71.32 .140(6)(\mathrm{b})$.

$501 \mathrm{Id} . \S 71.32 .140(2)(\mathrm{a})$. 
YALE JOURNAL OF HEALTH POLICY, LAW, AND ETHICS

XIV:1 (2014)

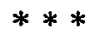

60 


\title{
APPEndiX A: Model Statutory PROVISIONS Governing MENTAL Health DIRECTIVES
}

\author{
Legislative Findings ${ }^{502}$
}

(1) Issues implicated in advance planning for end-of-life care are distinct from issues implicated in advance planning for mental health care.

(2) An individual with capacity has the right to control decisions relating to her mental health care.

(3) Mental illness is often episodic. Periods of incapacity obstruct the individual's ability to give informed consent and impede the individual's access to mental health care.

(4) Facilitating advance planning helps: (a) prevent unnecessary involuntary commitment and incarceration, (b) improve patient safety and health, and (c) improve care and enable patients to exercise control over their treatment.

(5) An acute episode can induce an individual to refuse treatment when the individual would consent to treatment if the individual's judgment were unimpaired. Empowering people to create self-binding mental health advance directives ("directives") to overcome their illness-induced treatment refusals protects patient safety, autonomy, and health.

(6) Individuals with mental illness have the same rights to plan in advance for treatment as individuals planning for end-of-life care. A directive can only accomplish the goals listed above if a patient may use a directive to:

(a) Set forth instructions for mental health care, including consent to inpatient mental health treatment, psychotropic medication, or electroconvulsive therapy;

(b) Dictate whether the directive is revocable during periods of incapacity and consent to treatment despite illness-induced refusals;

(c) Choose the standard by which the directive becomes active; and

(d) Designate an agent to make health care decisions for the patient.

Execution of Directives ${ }^{503}$

A directive shall:

(1) Be in writing;

(2) Be dated and signed by the principal or the principal's designated representative if the principal is unable to sign;

(3) State whether the principal wishes to be able to revoke the directive at

502 See id. $\S 71.32 .010$ (2013). The Washington statute inspired these model findings, which emphasize Ulysses arrangements even more than Washington does.

503 These provisions were inspired by WASH. REV. CODE. $\S \S 71.32 .050,71.32 .060,71.32 .090$ (2013). Unlike Washington, however, this provision requires a mental health professional attestation of principal capacity to form a Ulysses arrangement and allows principals who fail to address revocation to freely revoke. See id. $\$ 71.32 .070$. 
any time or whether the directive remains irrevocable during periods of incapacity. Failure to clarify whether the directive is revocable does not render it unenforceable. If the directive fails to state whether it is revocable, the principal may revoke it at any time.

(4) Contain a principal affirmation that the principal is aware of the nature of the document signed and signed the directive freely and voluntarily; ${ }^{504}$

(5) Be witnessed in writing by at least two adults. No witness may be:

(a) A member of the principal's treatment team;

(b) Related to the principal by blood, adoption, or marriage;

(c) Be in a romantic or dating relationship with the principal;

(d) The agent of the principal or a person designated to make health care decisions for the principal; or

(e) The owner, operator, employee, or relative of an owner or operator of a treatment facility in which the principal is a patient.

(6) Witnesses shall attest:

(a) They were present when the principal signed the directive;

(b) The principal did not appear incapacitated or under undue influence or duress when the principal signed the directive; and

(c) The principal presented identification or the witness personally knows the principal.

(7) Contain a written, signed attestation from a mental health professional that the principal had capacity at the time of directive execution, but only if the principal makes the directive irrevocable. If the principal is free to revoke the directive at any time, no mental health professional attestation of principal capacity is required.

(8) Be valid upon execution.

Activation of Directives

(1) Activation is the point at which the directive is used as the basis of decision making and dictates treatment of the principal. ${ }^{505}$

(2) Unless the principal otherwise designates in the directive, a directive becomes active when the principal loses capacity.

(3) The principal may designate an activation standard other than incapacity by describing the circumstances under which the directive becomes active.

(4) Despite activation, a directive does not prevail over contemporaneous preferences expressed by a principal who has capacity.

Role of Agents ${ }^{506}$

504 See Hargrave v. Vermont, 340 F.3d 27, 32 n.2 (2d Cir. 2003) (citing VT. STAT. ANn. tit. $14, \S 3456$ (2002) (which inspired this provision)).

505 VHA Report, supra note 10 , at 8.

506 See WASH. REv. CODE $§ 71.32 .100$, which inspired this provision. However, this model provision addresses an agent's role in a Ulysses arrangement. 
(1) In a directive, a principal may appoint an agent to make all health care decisions for the principal, including decisions to consent on behalf of the principal to electroconvulsive therapy, inpatient mental health treatment, and psychotropic medication.

(2) Express authorization to the agent to consent to the principal's inpatient mental health treatment and/or psychotropic medication is not required to convey authority to an agent to consent to such treatments. Rather, the agent may consent to such treatments for the principal if the principal's written grant of authority is sufficiently broad to encompass these decisions. However, an agent only has the authority to consent to electroconvulsive therapy for the principal if the principal expressly granted authority to consent to the principal's electroconvulsive therapy.

(3) An agent's decisions for the principal must be in good faith and consistent with the principal's instructions expressed in the principal's directive. If the directive fails to address an issue, the agent shall make decisions in accordance with the principal's instructions or preferences otherwise known to the agent. If the agent does not know the principal's instructions or preferences, the agent shall make decisions in the best interests of the principal.

(4) If the principal grants the agent authority to make decisions for the principal in circumstances in which the principal still has capacity, the principal's decisions when the principal has capacity override the agent's decisions.

(5) Except as otherwise prohibited by law, an agent has the same right as the principal to receive, review, and authorize the use and disclosure of the principal's health care information as is necessary for the agent to carry out the agent's duties for the principal.

(6) Health care decisions an agent makes for a principal are effective without judicial approval.

(7) When an incapacitated principal refuses inpatient mental health treatment and/or psychotropic medication, the principal's agent only has the authority to consent to such treatments for the principal if the principal's irrevocable directive expressly authorizes the agent to consent to the applicable treatment.

(8) A principal may not designate as her agent an owner, operator, or employee of a facility at which the principal is receiving care or a relative of such owner or operator unless the designated person is related to the principal by blood, marriage, or adoption.

\section{Permissible Scope of Directives}

In directives, principals may issue instructions or appoint agents to make decisions concerning all aspects of their mental-health treatment, except as limited by subsection (4) below, including:

(1) Consent to or refusal of specific types of mental health treatments, including psychotropic medication, electroconvulsive therapy, and inpatient 
mental health treatment; Consents to electroconvulsive therapy must be express;

(2) Preferences concerning treatment facilities and care providers;

(3) Nomination of a guardian for the court to consider if guardianship proceedings commence; but

(4) Principals may not consent to or authorize agents to consent to psychosurgery in a directive.

Revocation of Directives; Procedures for Implementing Self-Binding Arrangements, and Automatic Expiration only of Self-Binding Arrangements ${ }^{507}$

(1) Except self-binding arrangements as described in (5) below, directives remain in effect until they expire under their own terms or are revoked by the principal. Self-binding arrangements automatically expire two years after they are executed unless the principal reaffirms the arrangement. In the event the principal is incapacitated at the end of the two-year time frame, the self-binding arrangement remains in effect until the principal regains capacity and determines whether to reaffirm the arrangement.

(2) A principal may freely revoke a directive even if she is incapacitated unless the principal makes her directive irrevocable during periods of incapacity. To be irrevocable, the directive shall: and

(a) State that the directive remains irrevocable during periods of incapacity;

(b) Contain an attestation from a mental health professional that the principal had capacity at the time of executing the directive.

(3) A principal with capacity or a principal without capacity who did not make her directive irrevocable during periods of incapacity may revoke a directive by:

(a) A written statement revoking the directive;

(b) A subsequent directive that revokes the original directive. If the subsequent directive does not revoke the original directive in its entirety, only inconsistent provisions in the original directive are revoked; or

(c) Physical destruction of the directive with the intent that it be revoked.

(4) When a principal with capacity consents to treatment that is different than the treatment requested in her directive or refuses treatment that the principal requested in her directive, this consent or refusal does not revoke the entire directive but is a waiver of the inconsistent provision.

(5) A principal has a right to form a self-binding arrangement for care. Selfbinding arrangements allow the principal to obtain treatment in the event that an acute episode renders the principal incapacitated and induces the principal to refuse treatment. To provide advance consent to inpatient treatment despite the principal's illness-induced refusals, in her directive, a principal shall:

(a) Make her directive irrevocable pursuant to subsection (2) above; and

(b) Consent to admission in an inpatient treatment facility.

507 Also inspired by id. 
(c) If the principal wants administration of psychotropic medication despite the principal's illness-induced refusals of medication, the principal shall expressly consent to psychotropic medication in the irrevocable directive.

(6) If the principal forms a self-binding arrangement for treatment but then refuses admission despite the directive's instructions to admit, the facility shall respond as follows:

(a) The facility shall, as soon as practicable, obtain the informed consent of the principal's agent, if any is designated.

(b) Two mental health professionals shall within 24 hours of the principal's arrival at the facility evaluate the principal to determine whether the principal has capacity and to document in the principal's medical record a summary of findings, evaluations, and recommendations.

(c) The principal's statements in her directive requesting inpatient treatment upon activation of the directive, combined with activation of the directive, and contemporaneous refusals of treatment requested in the directive create a rebuttable presumption that the principal lacks capacity.

(d) If the evaluating mental health professionals determine the principal lacks capacity, the principal shall be admitted into the treatment facility pursuant to the principal's directive. The treating mental health professional shall document in the principal's medical records all treatment administered. After 21 days from the date of admission, if the principal has not regained capacity or has regained capacity but refuses to consent to remain for additional treatment, the facility shall release the principal during daylight hours unless the principal is detained pursuant to involuntary commitment standards.

(7) If a principal who has been determined to lack capacity continues to refuse inpatient treatment, the principal may immediately seek injunctive relief for release from the facility.

(8) If a principal with an irrevocable directive consenting to inpatient treatment refuses psychotropic medication through words or actions, only a licensed psychiatrist may administer psychotropic medication, and only if:

(a) The principal expressly consented to psychotropic medication in the principal's irrevocable directive; and

(b) The agent, if one was designated, consented to psychotropic medication;

(c)Two licensed psychiatrists recommend in writing treatment with the specific psychotropic medication. 